\title{
Developing an Innovation Engine for a web startup
}

\author{
by
}

David Ker

A thesis submitted to the Faculty of Graduate and Postdoctoral Affairs in partial fulfillment of the requirements for the degree of

Master of Applied Science

In

Technology Innovation Management

Carleton University,

Ottawa, Ontario

(C)2014

David Ker 


\begin{abstract}
The globalization of market is progressing steadily as barriers to the free flow of goods, services, and capital declined since the end of World War II. This trend results in substantial increase in foreign competitions, consequently it increases the needs for new ventures to better differentiate by other basis than cost and quality. The thesis at hand used a constructive methodology to design an improved entrepreneurial framework. The purpose of the research is to provide theoretical foundations for new ventures to better cope with business opportunities discovery. The core contribution of the research is the conceptual development through realworld application of the project space model, an element of the Innovation Engine described by Bailetti (2013), to help new technology venture to increase their chances of success in determining the right market niche. The research also tries to provide answers to the following research questions: $i)$ is the innovation engine model suitable for a web-based new ventures, ii) how can the project community component of the innovation engine be adopted by new ventures, iii) what processes new ventures can used to better cope with opportunity discovery?
\end{abstract}




\section{Acknowledgement}

I would like to thank my advisors Michael Weiss, Tony Bailetti, Daniel Blanchette, Jon Milne and Rajiv Muradia for their times, support, wisdom, and guidance. The patience of each has allowed me to pursue my research interests and comments have helped to me seek the big picture in my research and identify implications for my findings. Likewise, I thank my thesis committee members - Steve Muegge, Mika Westerlund - to guide my research and strengthen its technical contributions and experimental rigor during the gate reviews.

Though the pursuit of a Master may feel lonely at times, I am fortunate to have many friends and colleagues supporting me, and keeping me company along the way. To my new venture partners of many years — Fadhel Benslama and Eric Dumont — for the fond memories and much commemoration and commiseration of our ventures and startup lives, thank you.

To my office buddies in Cambodia and Canada (InvestOttawa) - George Borovec, Keng Pisey, Hok Malin, Te Soknyra, Chhay Sokoun, Lorn Se, Has Borey, Chhanh Trao, Song Soknay, Sreylin Doung, Kuch Darith, Chap Sovanyuth, Kong Kear and the rest of the team - for the inspiring memories and much sacrifices and commitments to ensure the venture survived, thank you. To my academic brothers\&sisters, Robert Poole, Mike Ayukawa, Nathasha D'Souza, Kenneth Esprit, Nadia Noori, Chris McPhee, James Makienko, Frank Horsfall, Mauricio Abreu \& Susana Macedo, for your listening ear and warm friendship, thank you.

To my parents for your immeasurable sacrifices and selfless love, for nurturing me in my formative years, and your continued support, thank you. To my love, Edith, for your many yup's to encourage me, nudging me through my work, and supporting me through many moments, taking care of the kids all by herself so that I can work on the startup and on the research. Thank you for always being here for me. 


\section{Table of Content}

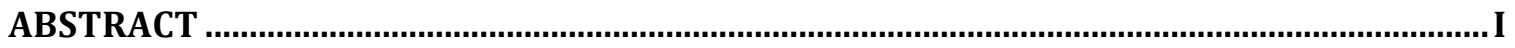

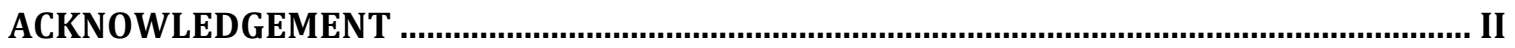

CHAPTER 1

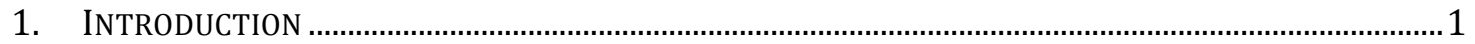

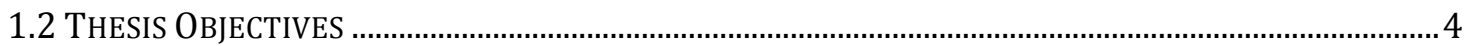

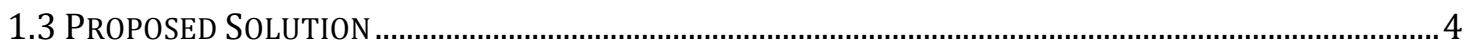

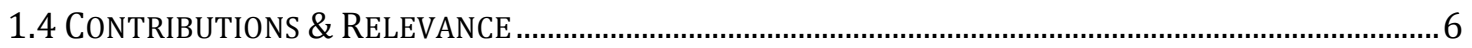

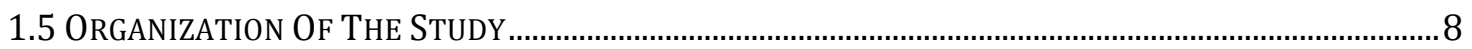

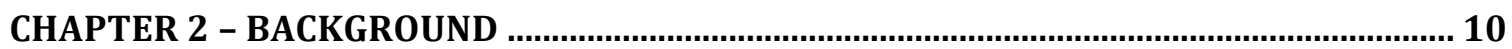

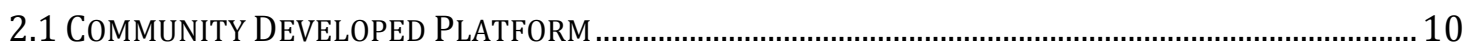

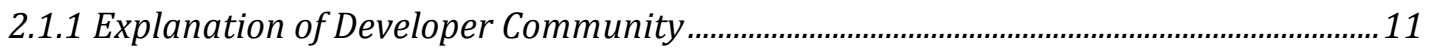

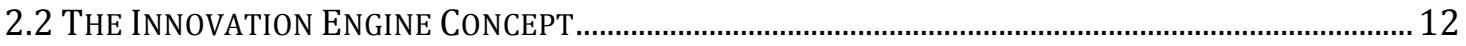

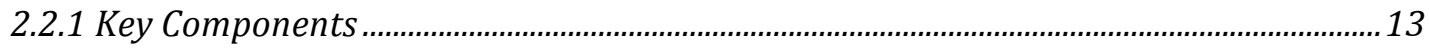

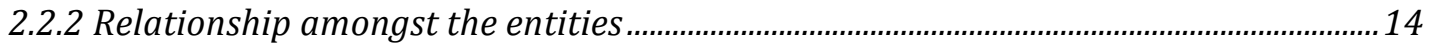

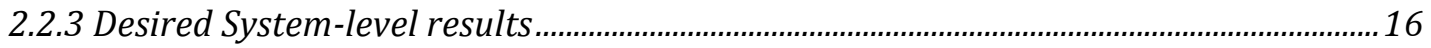

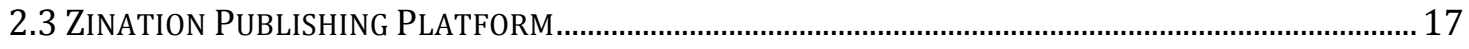

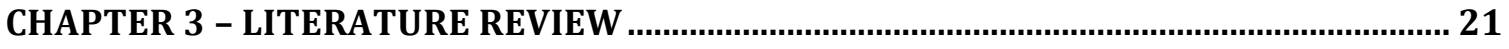

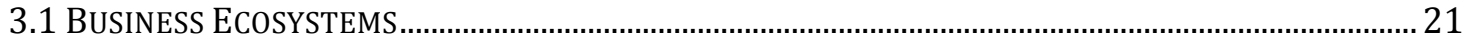

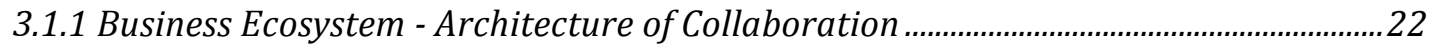

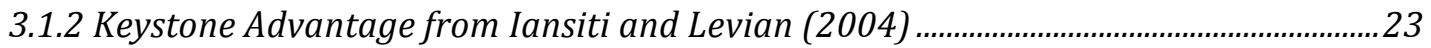

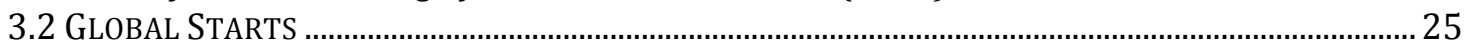

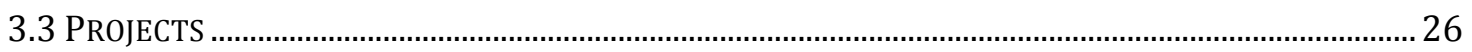

3.3.2 Project As Opportunities........................................................................................................2

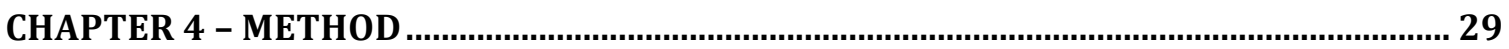

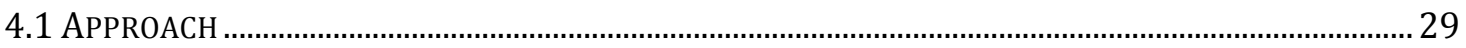

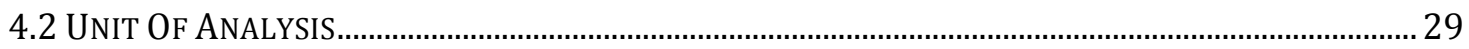

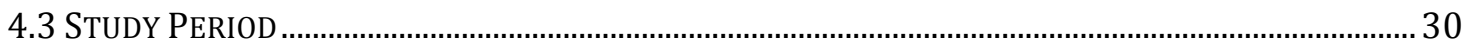

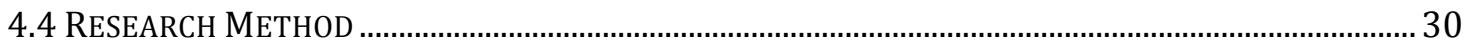

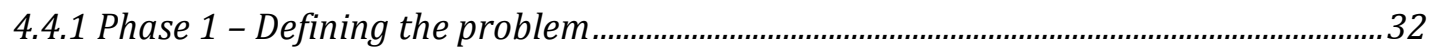

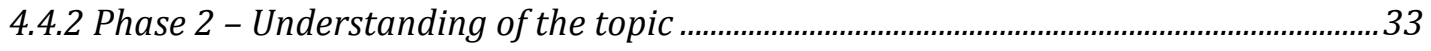

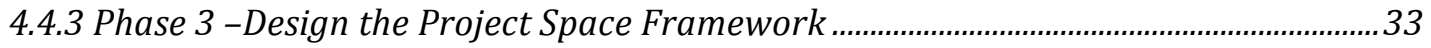

4.4.4 Phase 4 - Implementing the Solution and Gathering Data ...........................................33

4.4.5 Phase 5 - Showing the theoretical connections and research contribution...................34

4.4.6 Phase 6 - Examining the Scope of applicability of the Solution .........................................35

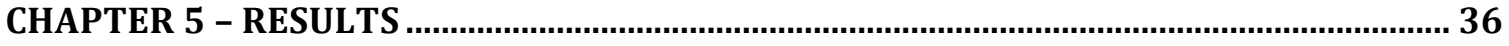

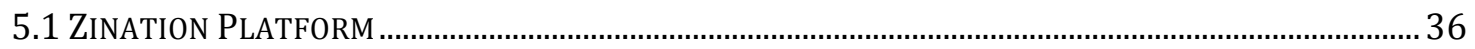

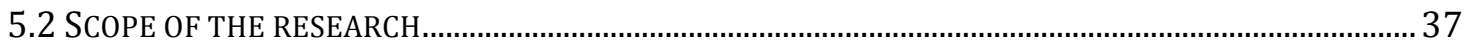

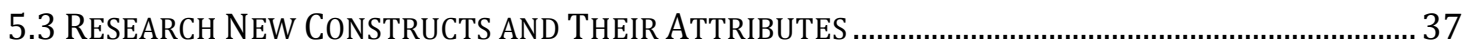

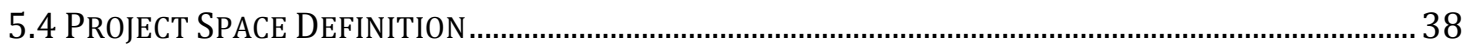

5.4.1 Definition of Project Probe..............................................................................................................

5.4.2 Definition of Project Space............................................................................................... 41

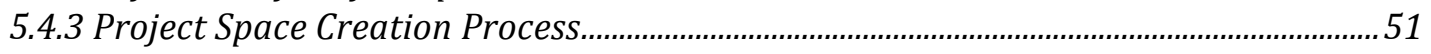

5.4.4 Project Space Framework - A framework for new market fit experimentation..........53

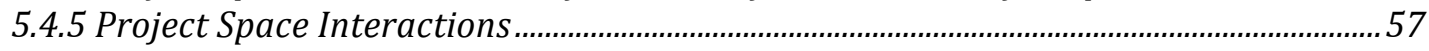

5.5 DATA FROM OPERATING THE INNOVATION ENGINE MODEL............................................................ 58 


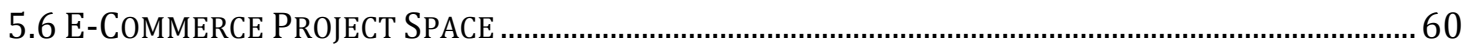

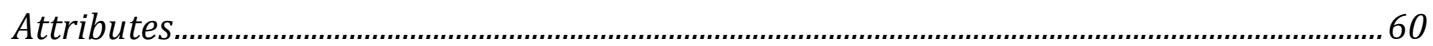

Probes.

Outcomes

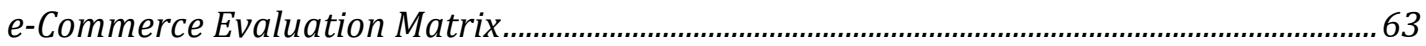

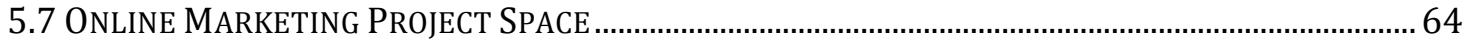

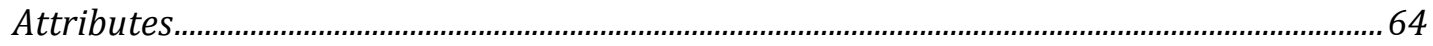

Probes.

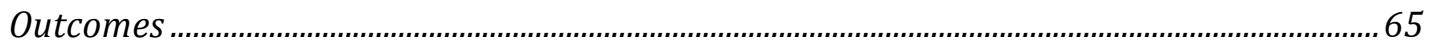

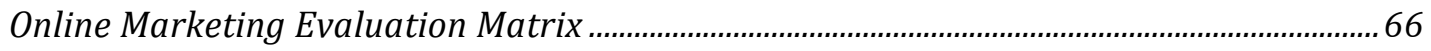

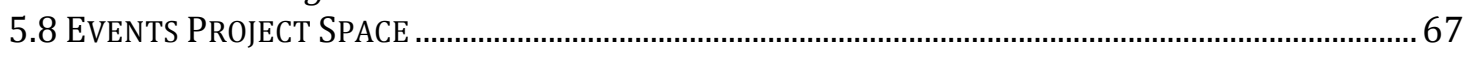

Attributes

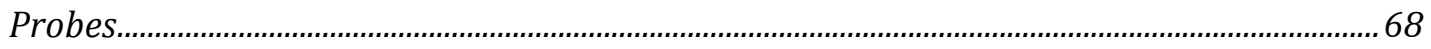

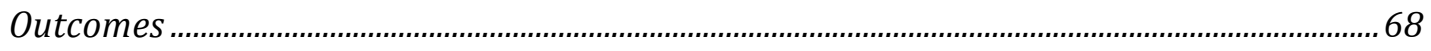

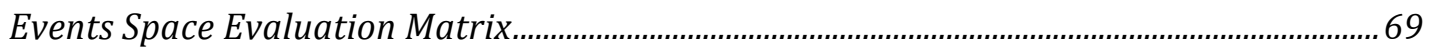

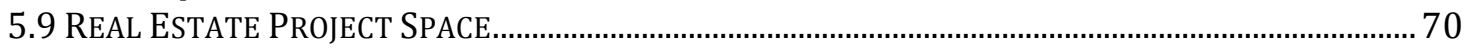

Attributes

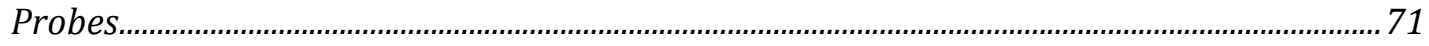

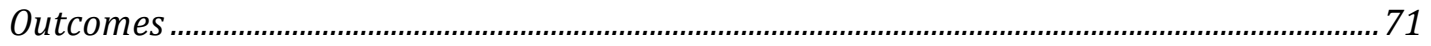

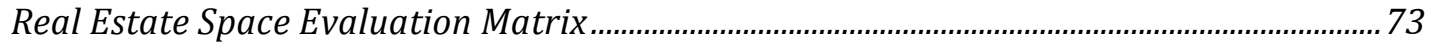

5.10 GENERIC PLATFORM INTEGRATION PROJECT SPACE ……............................................................... 73

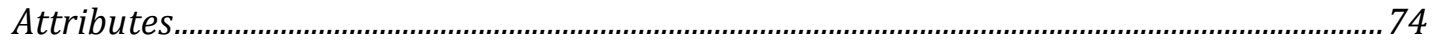

Probes

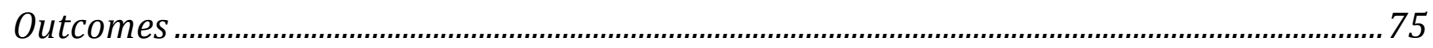

Generic Platform Integration Space Evaluation Matrix …...................................................... 75

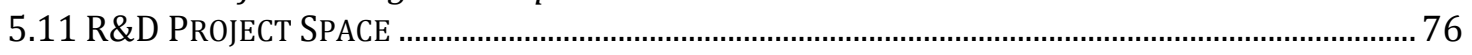

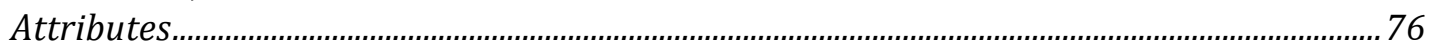

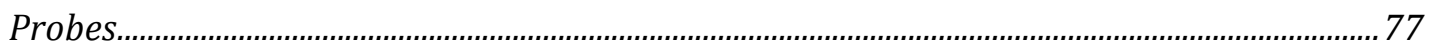

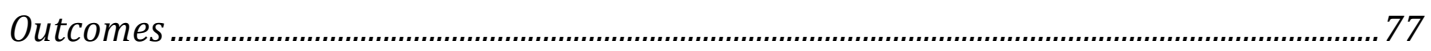

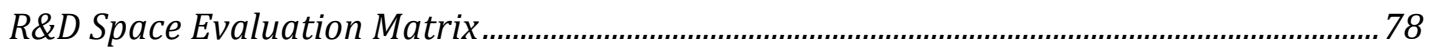

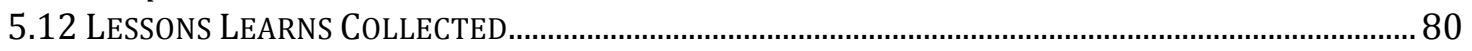

5.12.1 Lessons Learned from operating the Zination Platform ................................................8 80

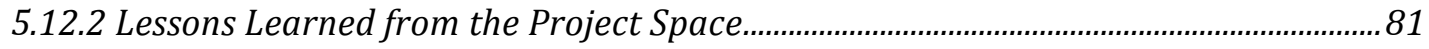

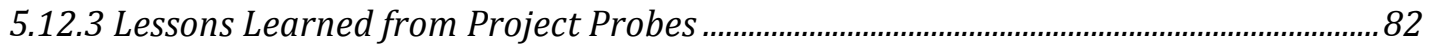

5.12.4 Lessons Learned from the Research Methodology ....................................................83

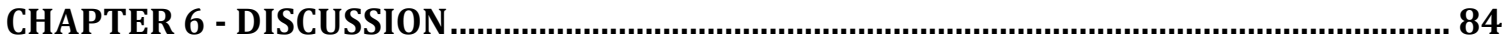

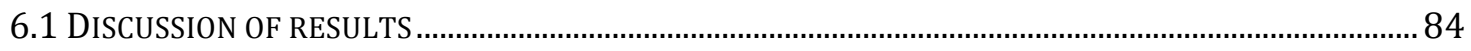

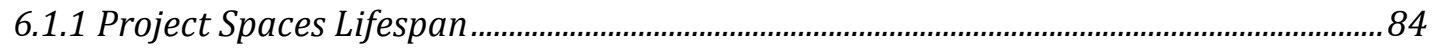

6.1.2 Summary of the results from operating the project spaces.............................................87

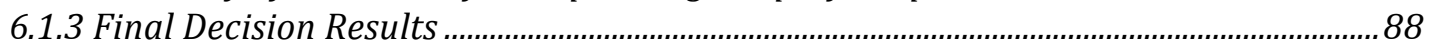

6.1.4 Project Space Attributes \& Outcomes Evaluation .............................................................94

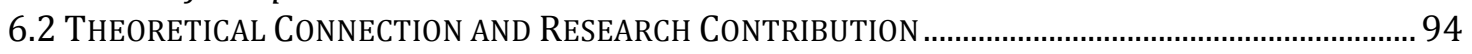

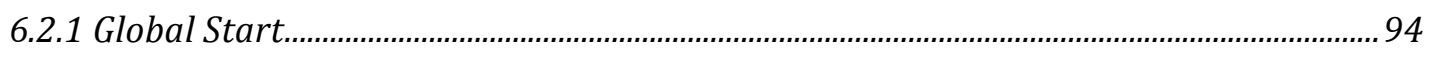

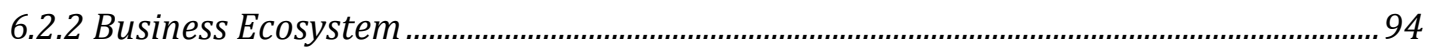

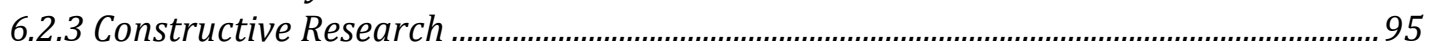

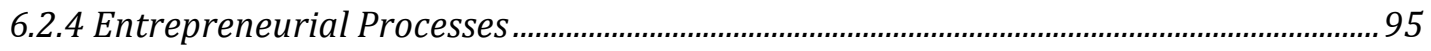

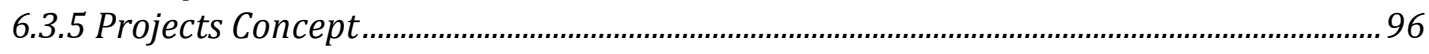

6.3.6 Project Space framework evolution during the research...............................................96

6.3.7 Links between Project Space Framework and Innovation Engine................................. 99 
6.4 RELEVANCY OF THE PROJECT SPACE FRAMEWORK FOR NEW VENTURES ........................................ 102

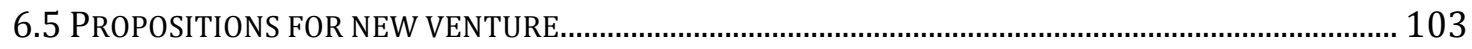

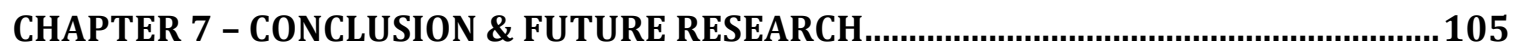

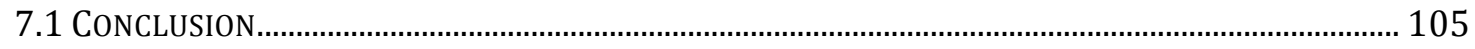

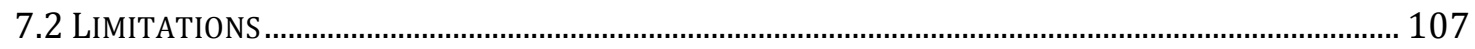

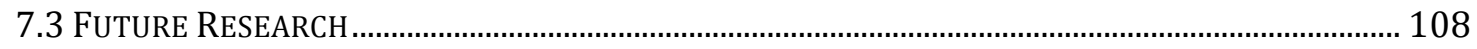

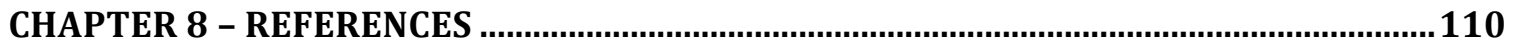




\section{List of Tables}

Table 1 - Lessons Learn from Business Ecosystem stream............................................. 24

Table 2 The benefits from collaboration from MacCormack et al. (2007)..................... 26

Table 3 -Research methods ............................................................................................ 31

Table 4 depicts the template for Data Collection for the Innovation Engine................ 34

Table 5 - Project Probe Attributes ......................................................................................... 39

Table 6 -Project Probe Outcomes ..................................................................................... 40

Table 7 -Project Space Attributes ....................................................................................... 43

Table 8 -Project Space Outcomes....................................................................................... 47

Table 9 -Three entrepreneurial processes and its activities ............................................ 48

Table 10 -Project Space Evaluation table based outcomes vs. entrepreneurial

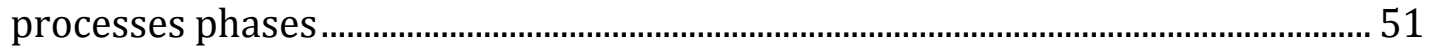

Table 11 summarizes the keys characteristics and relationship of the actors with respect to a project space .......................................................................................... 52

Table 12 -Project Space Case Studies ................................................................................ 58

Table 13 -Evaluation of E-Commerce Space ....................................................................6 60

Table 14 Evaluation of e-Commerce outcomes ………………………………………6 62

Table 15 -Phase Outcomes evaluation for e-Commerce space ......................................... 63

Table 16 -Project Space attributes evaluation for online marketing space ................... 64

Table 17 -Online Marketing project outcomes evaluation ……………………………. 65

Table 18 -Phase evaluation matrix for online marketing project space.......................... 66

Table 19 Project Space attributes evaluation for events management............................ 67

Table 20 Events Project Space outcomes evaluation ........................................................6 68

Table 21 Phase evaluation matrix for event project space............................................... 69

Table 22 Real Estate attributes evaluation table .............................................................. 70

Table 23 Real Estate Project Space outcomes.................................................................... 72

Table 24 Real Estate Phase Evaluation Matrixes ................................................................. 73

Table 25 Generic Platform Project Space Attributes Evaluation ...................................... 74

Table 26 Generic Platform project space outcomes evaluation ......................................... 75

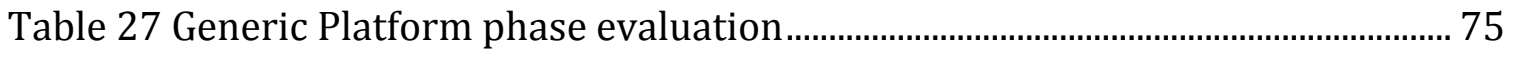

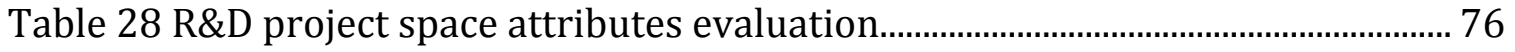

Table 29 R\&D Project space outcomes evaluation.............................................................. 77

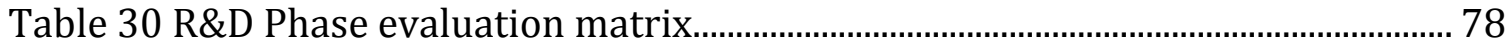

Table 31 summarizes the system-level results from each component of the innovation engine .................................................................................................... 79

Table 32 summarizes the project space progression during the research period..... 86

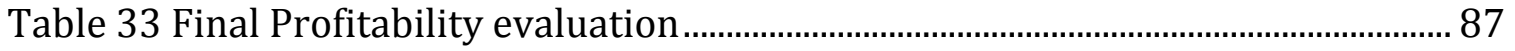

Table 34 summarizes final decision for each project space.............................................. 88 


\section{List of Figures}

Figure 1 Elements of the solution proposed.......................................................................... 5

Figure 2. Resource Cycle of Participation from Muegge (2011) ..................................... 10

Figure 3 depicts the Innovation Engine Components and its desired system-level

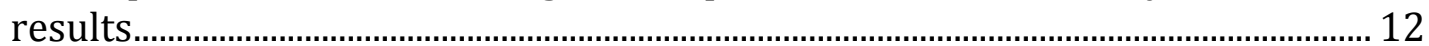

Figure 4 illustrates the relationships amongst all four entities ...................................... 14

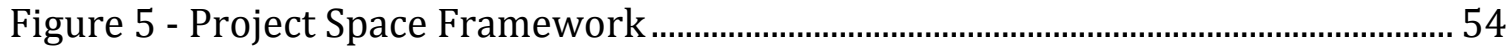

Figure 6 - Project Space progression during the research period..................................... 85

Figure 7 - Project Space Framework Evolution .................................................................. 97

Figure 8 - Links between the project space framework and Innovation engine components 


\section{Chapter 1}

\section{Introduction}

As the world moves further toward a global economy, competition will intensity while opportunities will increase. Dealing with expanded realms of opportunity, the most successful individuals and enterprises will be those that find ways to best leverage information to make decisions. As the economy interlinks and networks expand, it will be those entities that most efficiently acquire, manage and use information that succeed where others fail.

This is true for businesses, organizations and individuals alike. To succeed in any of these efforts requires managing, understanding and reacting to globally distributed sources of information, foreign customers, foreign partners, and opportunities.

Understanding and responding to the global challenge of development, efficient opportunity discovery methodology with the support of proper tools can help businesses to gain and maintain competitive edge.

To help business in gaining these edges, the design process examined in this research is based on the "Innovation Engine" architecture proposed by Bailetti (2013) for the Venus Cyber Project. The proposed innovation engine design was to cultivate the firm innovation culture to compete globally, provide a process driven methodology to innovation and bring external participants as part of the innovation process. One big contribution puts forth by Bailetti (2013) was to illustrate the components: A) The Organization, B) The Business Ecosystem, C) The Platform and D) The Project Community; the linking and relations of the engine and its components so that we can grasp the whole process visually. The contribution put forth by this research is by providing two additional concepts: the project space and the project probe. 
The following section discusses briefly the core concepts of the research.

\subsubsection{Global Start}

Global Starts (Englis et al., 2007) are business ventures that pursue opportunities anywhere on the globe the moment the business idea is developed.

These are business ventures whose goals are to expand internationally (day one), as opposed to adopting a gradual International expansion. Global Start strategy is to construct an organization that can scale rapidly and reach global marker rapidly. In that context, it mostly involved the development of Tech Solution, using web-based process to virally grow.

\subsubsection{Innovation Engine}

The concept of the innovation engine has been developed by Tony Bailetti to help Global Start entrepreneurs increase the odd while building a global organization. This innovation engine is the framework that guides the organizational design of this research.

\subsubsection{Keystone}

Keystone is a major concept that is used by this thesis to construct the global start organization, where most of the lessons learn is based on Iansiti \& Levian (2004). Literature describes key players as keystones. Keystones are conceptualized as catalyst or shapers of a business ecosystem. Weiss (2010) makes relevant clarification in describing: i) an ecosystem can contain more than one keystone, ii) some keystones can be common resources created by a group of organization to 
share risk or reduce cost, iii) a keystone concept is more of the idea of supplying the ecosystem with resources rather than being in charge.

We understand that it's very easy to confuse between creating a keystone organization using a platform play where the platform sit at the bottom of the value chain. This research uses the Keystone concept closer toward the idea of the shaper of the ecosystem.

\subsubsection{Project Definition}

According to Dictionary.com, a project is defined in some literature as a "large or major undertaking, especially one involving considerable money, personnel, and equipment" and time. Another definition from Archer \& Ghasemzadeh (1999), "a project can be defined as a complex effort, usually less than three years, made up of inter-related tasks, performed by various organizations with a well-defined objective, schedule and budget". Opportunity is closely related to the concept of a project argued Casson (2007). In essence, opportunity is a project that proves to be "beneficial if it were exploited".

These definitions are adequate, however the one from Casson (2007) is the closest

and most relevant for this research. A project is an opportunity that has been seized and tries out. Furthermore, the author argued that a set of opportunities is subjective because it reflects individual entrepreneur's perception of prospective profit. This definition from Casson (2007) differs from the general notion of a project as a unit of planning and organization of schedule. 


\subsection{Thesis Objectives}

\subsubsection{Problem and Purpose of this Study}

This research addresses the design of the Innovation Engine model for a web-based Global Start organization.

The research questions for this thesis are the following:

1. Is the innovation engine model suitable for a web-based new venture?

2. How can the project community component of the innovation engine be adopted by new venture?

3. What processes new venture can use to better cope with opportunity discovery?

The research tries to provide an answer to each of this research question by mean of a constructive research (Peffers et al., 2007) methodology.

\subsubsection{Gap in the literature}

There are little to non-existent literature on the research with respect to project space concept. Most researchers examine the project concept and the project portfolio concept. None is providing a methodology to do so using an innovative engine architecture that guides the process for the development of a project space. No literature is helping (in the context of the innovation engine model) in identifying the most profitable opportunity for new tech venture to pursue.

\subsection{Proposed Solution}

The research proposed to adapt the innovation engine for new tech venture, replacing the "project community" component by the project space component. The thesis examines how a project space is created and operated within a new venture in its early phase. The research proposed is new in the sense that it's tries to help 
new tech venture to identify new market space to explore in a more profitable and efficient method.

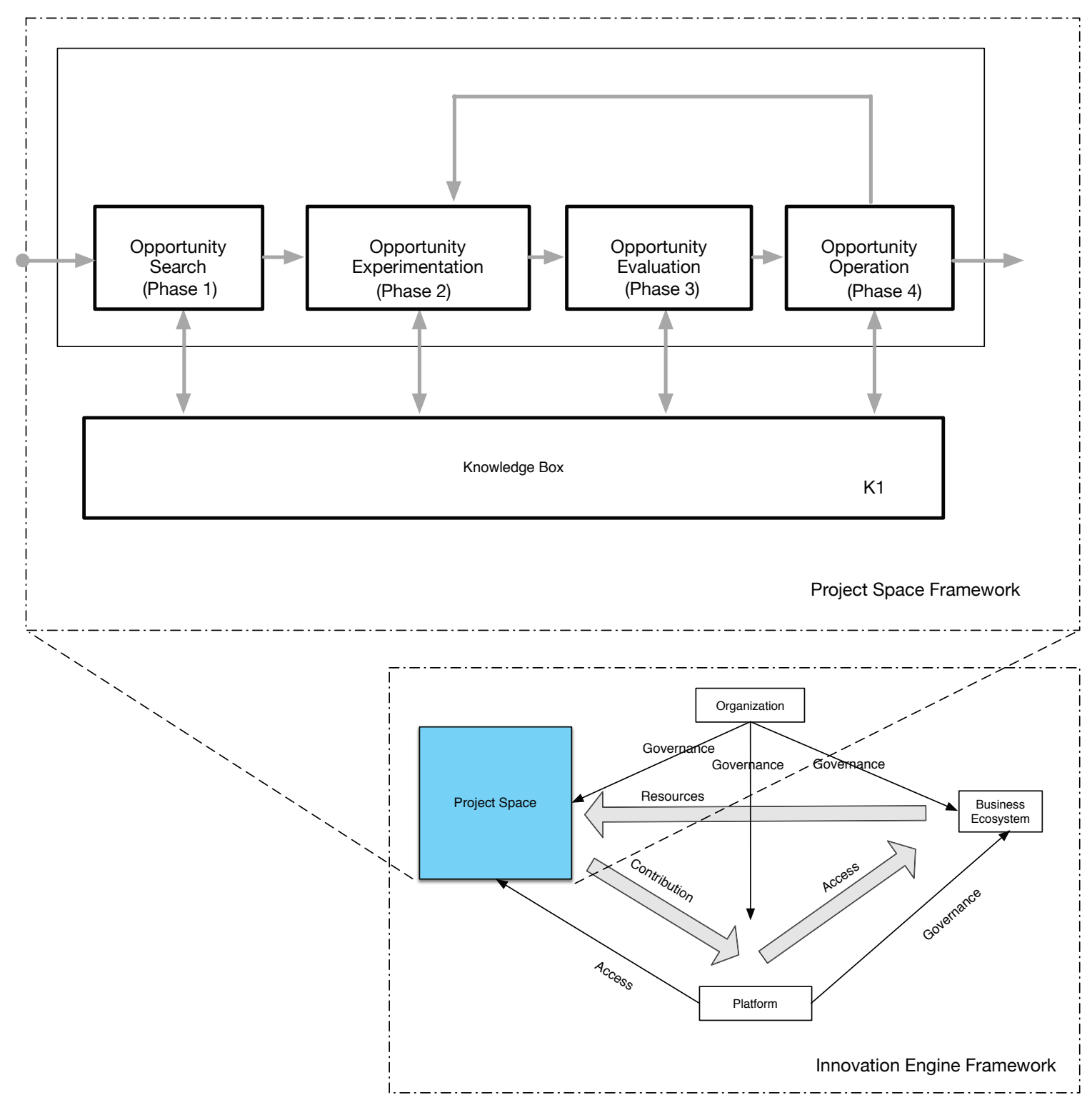

Figure 1 Elements of the solution proposed.

The proposed model is a combination of the innovation engine model, the phasegate process and the entrepreneurial processes. Figure 1 shows the elements of the solution proposed in this thesis. The creation and operation of a project space can 
be divided into four phases: i) Opportunity Search, ii) Opportunity experimentation, iii) Opportunity Evaluation and iv) Opportunity Operation.

\subsection{Contributions \& Relevance}

This research contributes to organizational design science by demonstrating how using an innovation engine framework can help new venture to shape their business.

Another major contribution of the research is to provide a methodology for opportunity discovery, a framework to identify the most profitable opportunity for new tech venture to seek, therefore providing a mean to increase the chance of success of a new venture.

In the original innovation engine framework (Bailetti 2013), the assumption was that projects are well defined. Within this adapted project space framework, in the context of new tech venture, projects are not defined, they have to be identified and tested against market needs before the new venture secures and commits more resources into a project. Bailetti (2012b) argues "Technology entrepreneurship is about creating and capturing value for the firm through projects that combine specialists and assets to produce and adopt technology". This research provides contribution in a method for populating the project space, therefore helping tech entrepreneur to create value through projects that pull together a subset of the ecosystem.

In brief, the value of project spaces is that it addresses the question of how the project community is populated. In the innovation engine framework the assumption was that projects were already well defined. 
The research employs the design approach (Peffers et al., 2007) to management research grounded on theory and practice (McPhee, 2012) to address this gap. The research is undertaken to provide a view to this problem that will enable entrepreneurs, researchers, and business practitioners to better gap the method used to identify and perform market fit experimentations, in the context of the operating a business around the innovation engine concept. The intent of the research is to contribute to help entrepreneur in improving their chance of success by better coping with market exploration.

This research delivers:

1. Lessons Learned. These are lessons from operating a new venture while adopting the innovation engine framework for a tech venture. The lessons are presented as proposition to help new ventures in better coping with opportunities.

2. A Project Space framework. A framework that provides guidance to new venture on how they can orchestrate the operation a new venture using more experimental methodology to find a better market fit. A project space concept to segment the market based on a defined job-to-be-done, with defined attributes and outcomes grounded on theory and experience. The research delivers a project probe concept to instill the discipline for the market validation before over investment into one venture. Finally it delivers a modified innovation engine model to take into account tech venture for-a-profit organization.

\section{Relevance}

This research is relevant for tech entrepreneurs in the process of creating or operating a new venture, it helps them to shape their business around the Innovation Engine model and operate the new venture following the project space framework to better experiment with the right market fit. By mean of this model, tech entrepreneur can make decision supported by measurements and evidencebased management practice. 
Researcher in general can learn from the constructive researcher methodology used and from the lessons learned from a real world new tech venture using the innovation engine framework.

This research is very much relevant to business stakeholders and business partners alike. These stakeholders can benefit from the successful operation of the new venture, from IP created, from job been created.

\subsection{Organization Of The Study}

The rest the research is organized as follows:

Chapter 2 describes the background information about the innovation engine by Bailetti (2013).

Chapter 3 reviews the literature on Global Start, Business Ecosystem, and Projects As Opportunities.

Chapter 4 analyses policies and structures more generally through defining a list of attributes. Various forms of concrete policies and structure are proposed by using the list of attributes from this formal analysis.

Chapter 5 presents the results from designing an innovation engine with a project space framework and results from operating the engine in a real use case.

Chapter 6 uses the results from Chapter 5 to explain why the Innovation Engine is a relevant framework for web-based new ventures, and then adapt the engine for a for-profit organization. Then our proposed methodology is explained through real examples. 
Chapter 7 draws conclusion, describes contributions and suggest future areas of research.

Chapter 8 provides references for this research. 


\section{Chapter 2 - Background}

This chapter reviews the background concepts behind this research.

The chapter is organized into three sections. The first section covers the Community Developed platform; the second section discusses the innovation engine model and the third section covers the Zination publishing platform.

\subsection{Community Developed Platform}

Previous to the innovation engine model, Muegge (2011) paper on building business ecosystem as institutions of participation describes in a high level the major components of the future innovation engine model by Bailetti (2012): the Governance Foundation, the Business Ecosystem, the Community-Developed Platform and the Developer Community.

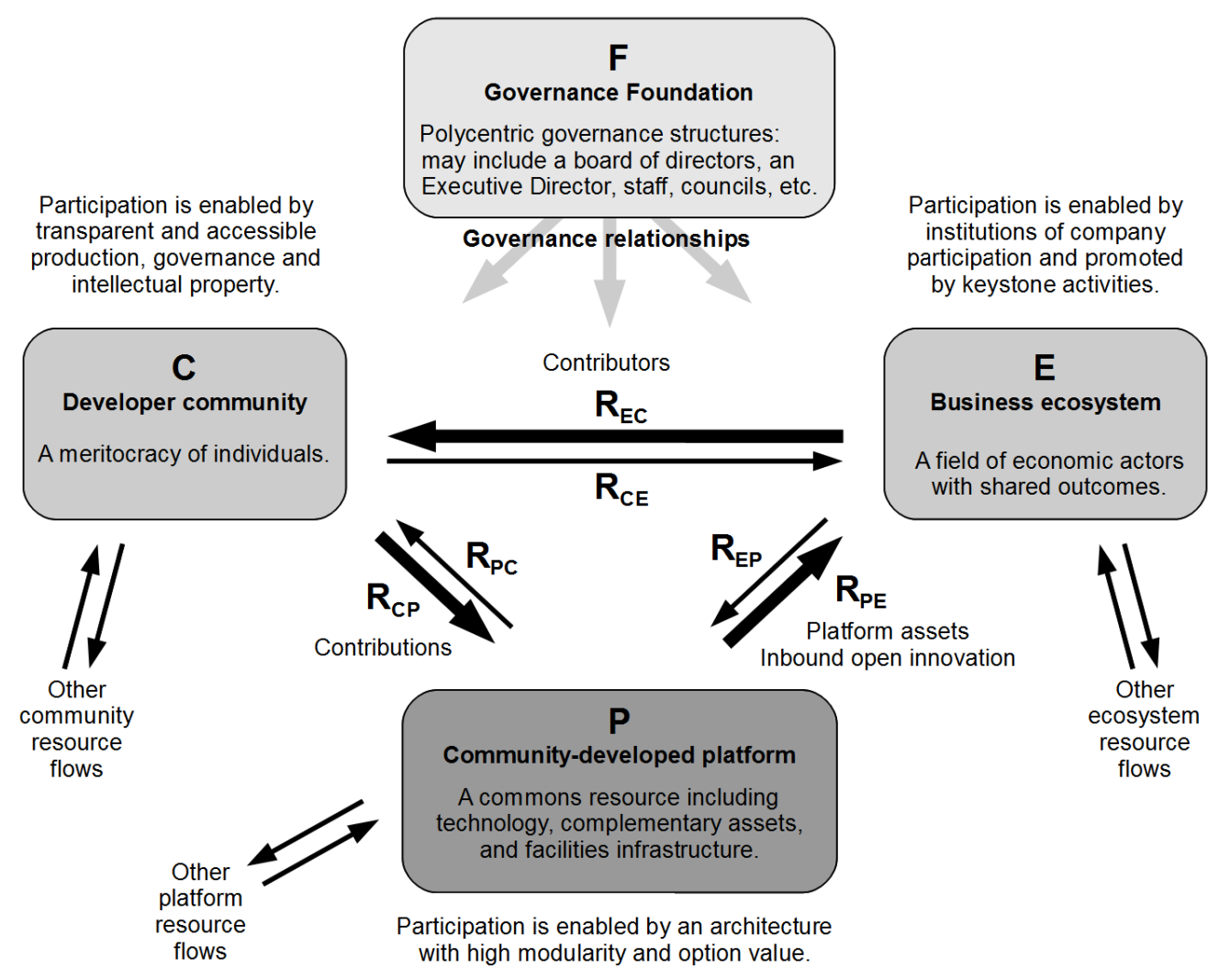

Figure 2. Resource Cycle of Participation from Muegge (2011) 
This research is particularly interested in the Developer Community (C) component, the rest are covered in Muegge (2011) paper.

\subsubsection{Explanation of Developer Community}

In Muegge (2011), the author defines the developer community as "the community of individuals, organized as a meritocracy, who collectively maintain and extend the platform". The developer community, like a business ecosystem, operates within an institution.

The author argues in a meritocracy community, it's the individuals, not the organization employing those individuals that have merit and status. Three key findings from previous research are relevant to note. First, there are a large variety of motivation and incentives for individual participation. Second, in many open source project, developers are employed by companies to work on an open source software fulltime. Third, the author argues research has identified many of the institutional factors associated with participation in developer communities. Based on the author, the engine driving innovation on community-developed platform is a resource cycle from the platform (P), to the business ecosystem (E), to the developer community (C), back to the platform (P). Additionally, the author indicates, "The developer community is the locus of innovation creation and platform value creation, and the business ecosystem is the locus of innovation commercialization and platform value capture. The platform is the outbound product of the developer community and inbound open innovation for the economic actors of the business ecosystem."

Developer community differs from the project space in many aspects. A developer community gathers individuals together to tackle a known problem, task. A project space is an opportunity discovery model to identify the problem to be solved. A project space is to determine the market needs, it has to deal with many uncertainties and is designed to explore new area. 
As described in later sections within this research, the cycle is similar to the project space framework. The difference resides in the starting point been the project space component, as opposed to the platform.

\subsection{The Innovation Engine Concept}

The proposed innovation engine architecture described in this research is an adaptation of the Innovation Engine from Bailetti (2013)'s model. The original model is utilized with the intent to create a framework that can produce desired system-level results and can provide the new firm advantages to compete globally.

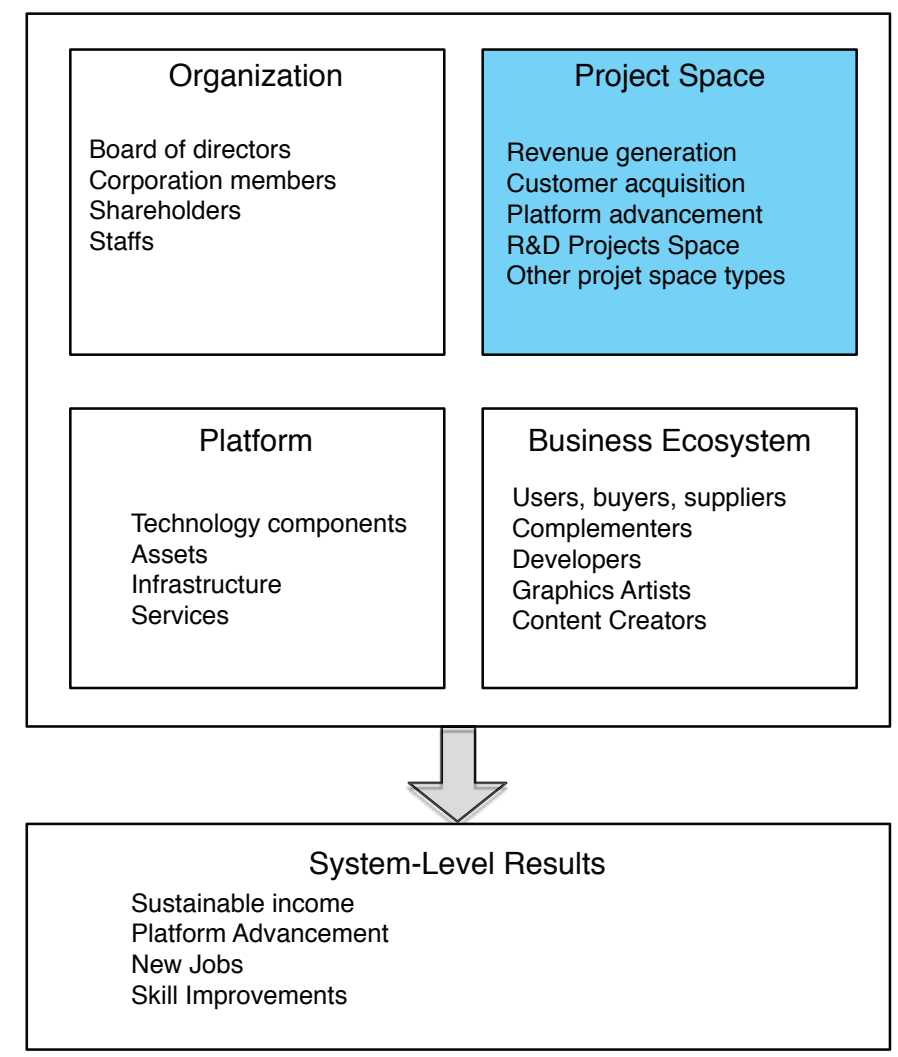

Figure 3 depicts the Innovation Engine Components and its desired systemlevel results 


\subsubsection{Key Components}

The four key components of this innovation engine are adapted to allow the organization to be competitive in the new global economy:

1. Global Start Organization

2. The Platform

3. The Business Ecosystem

4. Project Space

\section{The Organization Component}

The organization component is the result of the structured collaboration and commitment for the advancement of the platform. The organization comprises of participants, which commits resources, funds, and time for the operation of a project space. It provides the strategic intent of the entire project space. The organization component provides governance over the entire innovation engine.

\section{The Platform Component}

The platform comprises of technologies, infrastructure, assets and services. Project space, organization and business ecosystem participants will be able to use and consume the elements of the platforms.

\section{Business Ecosystem}

The business ecosystem is the highest level of abstraction. Members of the business ecosystem include buyers, users, customers, partners, channels, etc. The innovation engine intends is to serve the business ecosystem.

\section{The Project Space}

Within Muegge (2011), the project space element represents the developer community. In Bailetti (2013), it evolves into a Project Community. Based on the author, a Project Community "comprises the individuals working within a project portfolio sanctioned by the [...] [organization]. Projects are defined and organized by their desired [...] knowledge, technology, and business outcomes". 
Within this research, this element evolves further into an element designed to tackle specific niched problem and market. More detail is provided in the following sections.

\subsubsection{Relationship amongst the entities}

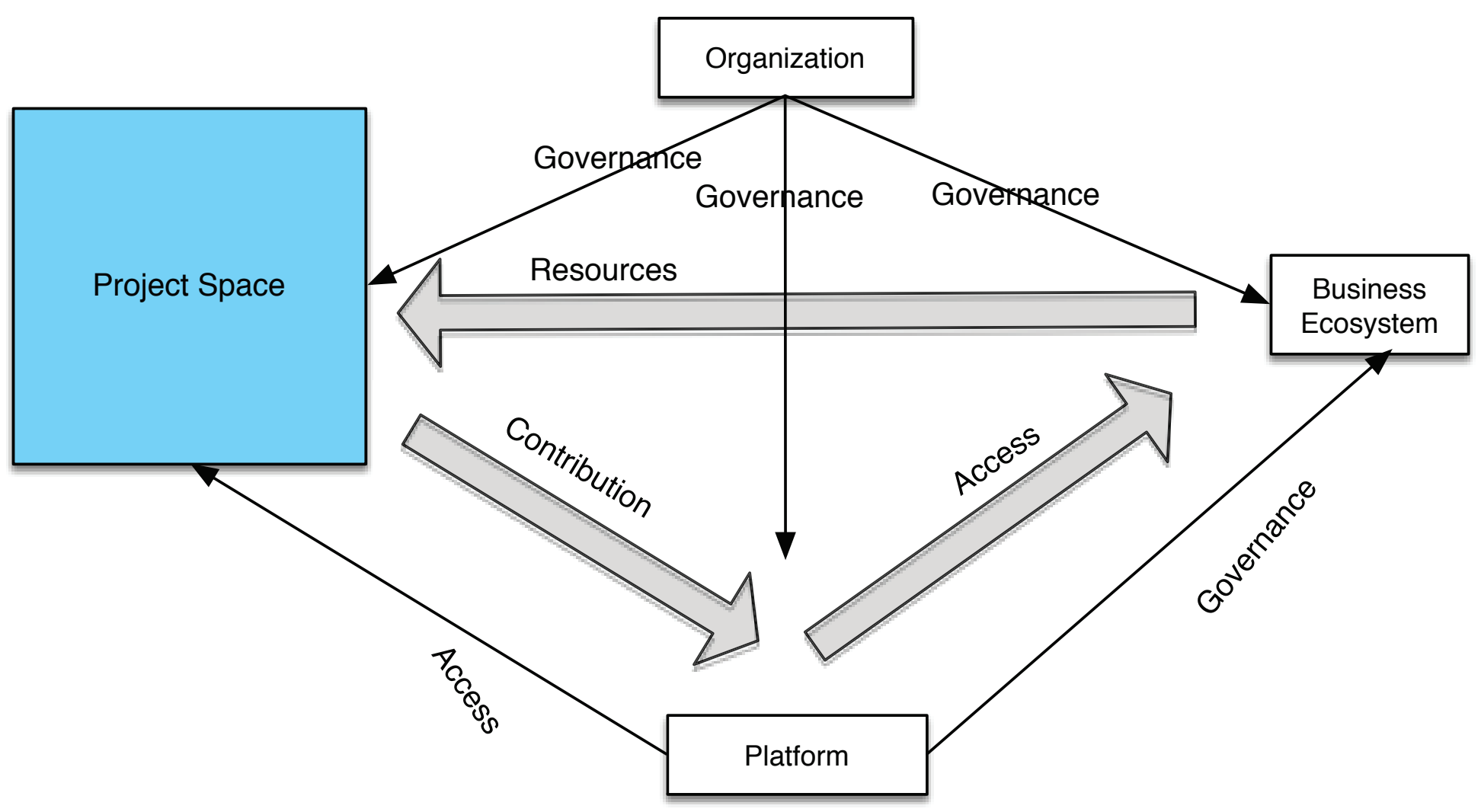

Figure 4 illustrates the relationships amongst all four entities

Figure 4 depicts the relationships among components of the innovation engine, comprising of the Global Start Organization, the Business Ecosystem, the Project Space and the Platform. This innovation engine is designed with the intent to produce the system-level desired results. As described by Bailetti (2013), the inner 
triangle illustrates the resource cycle of the innovation engine, which moves from the Project Space to the Platform, to the Business Ecosystem, back to the Project Space.

In the context of this research, similar to Bailetti (2013) Project Community element, the Project Space is the focal point of innovation in R\&D. Through the Project Space element, the engine is able to tackle specific problems in a global niche, leverage the ecosystem and the platform into new technology components, assets and services, which enable advancement of the platform and provide a source of revenue generation for the organization.

The Business Ecosystem is the element of the ecosystem bringing many participants (customers, end users, partners, suppliers) who will consume the offering provided by the Platform in the form of technology components, assets and services.

Organizational agreements, defined by the protocol of collaboration (Snow et al., 2012) and participation within the ecosystem, will enable the following activities to take place:

1. Members of the business ecosystem will be able to use and extend the assets of the Platform to create and capture value.

2. Project Space operation and experimentation will be able to contribute new technology components and assets to the platform, and lessons learn from experimentation to the Organization.

3. Members of the business ecosystem will be able to contribute assets to the Platform. 


\section{The Organization Element}

The Organization element of the innovation engine is an organization, corporation that represents, within this research, a Keystone which anchors the innovation engine as depicts in figure 4.

As discussed in Bailetti (2013), the Organization has four key responsibilities:

1. To sustain the strategic intent of the innovation engine.

2. To govern the operation of the innovation engine.

3. To increase the Platform relevancy within the business ecosystem.

4. Provide access the Platform to members of the business ecosystem.

\subsubsection{Desired System-level results}

The following section illustrates the system-level results expected from operating the innovation engine. In the context of this research, we identify four core systemlevel results for operating the innovation engine.

\section{Market Intelligence}

Market intelligence is the result by which by operating the innovation engine, the organization understands which niche market and problem to tackle into the most efficient way. Solving a problem that is not desired by the marketplace is non productive and won't allow the engine to survive over a long period.

\section{Platform Advancement}

Platform advancement is the second desired result. By operating the engine, the platform can progress and increase in value overtime, hence bringing more values to the entire business ecosystem and the organization itself.

\section{Training ground to build qualified people}

Third result is in increasing and producing trained people in the field of management and IT on how to operate an innovation engine and be able to manage 
a global company. By operating the innovation engine in the market of digital online marketing and e-commerce, the people behind the operation of this innovation engine develops core expertise that are hard to find.

\section{Income for the organization}

The fourth desired-result is to produce income for the organization such that it allows the organization to create jobs, create wealth for all stakeholders.

\subsection{Zination Publishing Platform}

The organization (further referred as "The Company") responsible for the governance of the innovation engine studied has been created just before the research started. The Company is an innovative Born Global company in the newly emerging field of Mobile, Web 3.0 and Online Marketing Market. Materialization of The Company market offer resulted in the Zination Platform.

Zination Platform value propositions are as follow:

"An online tool to help business shines on all screens easily, affordably, instantaneously".

- Zination helps business standouts from the crowd by mean of exceptionally beautiful Zine that is SEO friendly, which can be created rapidly with no expertise required.

- Beautiful Zine can be easily created by assisted graphic design ecosystem.

- Allowing some marketing automation.

- Providing exceptional user experience on all screens.

- Providing means to reach out customers in the easiest and most convenient manner.

The Company is architected to adopt Global Start principles and to tackle a global but niched problem. The global problem and opportunity comes from this global trends: 
a. Hyper-connected consumer (pc, mobile, everywhere, every time);

b. Active and at the same time distracted consumers;

c. Marketing is in a massive transformation period; and

d. Every brand is becoming a publisher.

These trends generate new pains for businesses (anywhere in the world) to attract prospects, acquire customers and make sales in this new environment.

One answer to that problem resides in the understanding that business needs to be differentiating, get their customers attention and retain them by all means.

The global opportunity for The Company resides in creating a Keystone Organization around the Zination Platform, which can profit from this problem/opportunity, hence enabling the following revenues streams for the Keystone Organization:

1 Delivering services to customers;

2 Charging subscriptions for cloud-based offerings; and

3 Charging transactions fees for access to the commons assets.

The Company is currently developing the Zination product and service to allow the organization to be the keystone organization for the Zination ecosystem. The Zination Keystone Organization anchors a community of individuals and organizations that share and evolve the Zine common assets using protocols defined by the Company. The creation of the Zination ecosystem is designed around an organizational architecture to enable business ecosystem participation.

The individuals and organizations in this new ecosystem can be graphics artists, web development shops, application programmers, content creators, authors, media publishers, mobile app store, etc. These are suppliers, complementors, channels distributors who will profit from participating in this ecosystem and enrich the value of the whole ecosystem. 
The commons assets are Zine ${ }^{\mathrm{TM}}$, post, photos, videos, widgets, media contents, website templates, curated contents, classification, ratings, comments, RSS news, web shopping content, classified, source code, and digital assets (photo, video, music).

The Zination protocols to allow the common assets to evolve and shared amongst the stakeholders resides firstly in defining the specific rules and recommendation to ensure that the common assets can be used and distributed within the community.

The protocol to insert content into the common asset can be of two types:

- General public license content distribution agreement type, in which case the author gives the right to the community to share and evolve the content

- Transaction based license agreement type, in which case the sharing and consumption of the asset comes with a fee.

Technology Behind the Zination Platform

Zination is an innovative platform enabling businesses and marketers to publish business contents in web standard format (HTML5) that is mobile friendly in a digital Zine ${ }^{\mathrm{TM}}$ metaphor, which can be pushed out into multiple channels, including native mobile app.

The first most important value proposition comes from making the process to create beautify online content extremely easy and fast. The Platform wants to become an "Instagram" for web content publishing.

The second value proposition comes from allowing content consumption of digital content on all screens such that the user experience is the center state, absolutely unique, touching.

The third value proposition is the consistency in the user experience on all devices. This can be achieved by using a common Zine metaphor for the presentation layer. The third strongest value proposition is served by offering solutions to business 
owners tools and processes to gather intelligence about its customers and mechanism to reach them.

Hence, this research is a real world practical use case where theory and practices are applied on a real organization and design of the platform is supported by a real world market offer. The benefits of this research are two folds: it helps improved the managerial literature on the innovation engine concept; additionally it also helps stakeholders behind the Company to produce real organizational results. 


\section{Chapter 3 - Literature Review}

This chapter reviews the literature streams that are relevant to the research. The chapter is organized into three sections. The first section reviews the literature related to the business ecosystem domain, the second section covers the Global Start stream and the third section reviews the Project As Opportunities domain of knowledge.

\subsection{Business Ecosystems}

As companies' innovation accelerates, they discovered that they couldn't bring their innovation to the world by themselves Moore (2006). For every advance, complementary innovation must be joined in order for customers to benefit. Moore (2006) defines business ecosystem as "an intentional community of economic actors whose individual business activities share in some large measure the fate of the whole community". A second definition from the same author define business ecosystem as "a network of interdependent niches that in turn are occupied by organizations". In an ideal business ecosystem, members are motivated to work together to benefit the entire community.

Snow (2012) argues, "Multiparty collaboration is critical to the effective solution of complex problems and continuous adaptation to changing environment". Large scale collaboration behaviors amongst actors (who follows protocols for sharing resources) reward both within and across firms.

A lesson for manager to keep in mind, if building a business ecosystem is intended to be resilient, managers must understand the properties that enable an ecosystem to maintain its integrity in face of changing environment Levin (1998).

Gulati \& al (2012) identified key parameters on which me-organizations differ from each other. The dimensions open/closed boundaries versus low/high 
stratification/hierarchical decision-making can guide in the design of the business ecosystem by mean of a well-defined table for classification.

Within the broad question of how to best organize the development and commercialization of a technology platform, the two approaches to opening the platform Boudreau (2010) are granting access versus devolving control. Granting access to the platform allow complementors to innovate and participate. This strategy can produce up to fivefold the adoption of innovation byproduct. Yoffie \& Kwak (2005) discuss the art of managing complementors, when a platform needs complementors and how it should cultivate them.

Another method to opening up the platform is by mean of an open source strategy. West (2008) found that sponsored open source communities tend to favor transparency versus accessibility. The balance between the two are important has implication for he communities growth.

Schilling (1998) argues that for many industries, new product development is now the single most important driving firm success or failure. This statement is arguably generic, but it provides some insight into how a new development process is required to help increase the odd. The authors state also how for firm to succeed, they must maximize the fit with customer needs and minimize time to market. Additional lessons learn from the article are with respect to the strategic imperatives that have been shown to improve the new product development.

\subsubsection{Business Ecosystem - Architecture of Collaboration}

Snow et al. (2012) argue firms are increasing facing competitive pressures due to rapid continual adaptation and the new global inter-connected economy. In that context, they noted new experimentation occurs with respect to organization designs that are different from current form. Consequently, the authors propose that new designs should be actor-oriented architectural scheme, an architecture that is "composed of three main elements: 1) actors who have the capabilities and 
values to self-organize; 2) common where the actors accumulate and share resources; 3) protocols, processes, and infrastructures that enable multi-actor collaboration".

Baldwin \& Clark (2006) argue the architecture of a code base is a critical factor "that lies at the hearth of the open source development process", hence critical to enable participation. The author further argues there are two observable properties of participative platform architecture: 1) modularity and 2) option value. The authors show that a platform architecture that is more modular or has "more option value (1) increase developers' incentives to join and remain involved in an open source development effort and (2) decrease the amount of free riding in equilibrium".

\subsubsection{Keystone Advantage from Iansiti and Levian (2004)}

Iansiti and Levian (2004) discuss business ecosystem as an analogy, which can help to describe and understand issues related to Global Start. "We found that perhaps more than any other type of network, a biological ecosystem provides a powerful analogy for understanding a business network. Like business networks, biological ecosystems are characterized by a large number of loosely interconnected participants who depend on each other for their mutual effectiveness and survival. And like business network participants, biological species in ecosystems share their fate with each other. If the ecosystem is healthy, individual species thrive. If the ecosystem is unhealthy, individual species suffer deeply. And as with business ecosystems, reversals in overall ecosystem health can happen very quickly." (Iansiti \& Levien 2004, 8-9).

Furthermore, the authors argue there are three success factors of a business ecosystem. First, productivity will define the success of any kind of business. Second, a business ecosystem must be robust. Third, a business ecosystem should have the ability to create niche and opportunities for new firms. It requires a change in attitude toward cooperation instead of protectionism. 
Table 1 - Lessons Learn from Business Ecosystem stream

\begin{tabular}{|c|c|}
\hline $\begin{array}{c}\text { Business Ecosystem } \\
\text { Elements } \\
\end{array}$ & Lessons Learn \\
\hline \multicolumn{2}{|l|}{ Platform Building } \\
\hline & $\begin{array}{l}\text { Provide solution to general problems. } \\
\text { Balance implementation and interface design } \\
\text { Selectively open the platform to balance } \\
\text { distributed innovation with control needs. } \\
\text { Leverage platform provided by others but } \\
\text { manage switching cost. } \\
\text { Architecture \& standards } \\
\text { Integrate tools to implement popular } \\
\text { standards into the platform. }\end{array}$ \\
\hline \multicolumn{2}{|l|}{ Integration } \\
\hline & $\begin{array}{l}\text { Leverage deep knowledge of internal and } \\
\text { external domains. } \\
\text { Overlap conceptualization and implementation } \\
\text { but don't sacrifice architecture. } \\
\text { Merge experimentation and experience. }\end{array}$ \\
\hline \multicolumn{2}{|l|}{ Market Management } \\
\hline & $\begin{array}{l}\text { Achieve liquidity first. } \\
\text { Price to balance communities. } \\
\text { Design a flexible market. } \\
\text { Practice experimentation market adoption. } \\
\text { Leverage the ecosystem. } \\
\text { Minimize internal market positions. } \\
\text { Create and manage trust. } \\
\text { Define a clear market governance structure. }\end{array}$ \\
\hline \multicolumn{2}{|l|}{ Value Creation } \\
\hline & $\begin{array}{l}\text { Create high-value, shareable assets. } \\
\text { Leverage direct customers connections. } \\
\text { Create and manage physical connections. } \\
\text { Create, package, and share state-of-the-art } \\
\text { tools and building blocks for innovation. } \\
\text { Support uniform information standards } \\
\text { Reduce uncertainty by centralizing and } \\
\text { coordinating communication. }\end{array}$ \\
\hline
\end{tabular}




\subsection{Global Starts}

Creating a new firm that is global at inception presents many risks and challenges. Within the new global economy, new tech firm must face swift competition from all around the world. In that competitive environment, Bailetti (2010), six elements are essentials for a new firm to get right: i) problem scope, ii) stakeholder commitments, iii) collaborative entrepreneurship, iv) relational capital, v) legitimacy and vi) global capability.

Additionally, to secure sustainable competitive advantage, new firm can develop an innovation engine Bailetti (2013). The innovation is comprised of five components: i) the platform, ii) the business ecosystem, iii) the project community, iv) the corporation and $v$ ) the external community. The entire engine with the interaction between all five entities and the governance rules allow an organization to compete globally.

MacCormack et al. (2007) points out how global collaboration is a new source of competitive advantage. The author argues many firms are applying mistakenly an outsourcing mindset to collaboration effort, which led to three critical errors: first, firms focused solely on lower costs, second firms didn't organize effectively for collaboration and manage innovation like a suppliers, third firms didn't invest in building collaborative capabilities. Successful firms, on the contrary, are developing strategy for collaboration and "made organizational changes to aid performance in these efforts". This can be achieved by mean of two methods: by leveraging a partner's superior capabilities, and by accessing partner's contextual knowledge. The author proposed the 3C of a Global Collaboration Strategy Framework: Cost, Capability and Context.

The following table illustrates the benefits from collaboration based on the $3 \mathrm{C}$ framework.

\begin{tabular}{|l|l|l|}
\hline Lower Costs & Superior Capabilities & Contextual Knowledge \\
\hline Low cost labor & Rapid access to capability & Market access \\
\hline
\end{tabular}




\begin{tabular}{|l|l|l|}
\hline Low cost materials & Technical know-how & Supplier relationships \\
\hline Low cost suppliers & Process expertise & Institutional ties \\
\hline Low cost infrastructure & Domain Knowledge & Government connections \\
\hline
\end{tabular}

Table 2 The benefits from collaboration from MacCormack et al. (2007)

Englis et al. (2007) discusses the importance of knowledge and networks in global startup process. Global start, as described by the authors, is a new venture that pursues opportunities around the globe the moment the business idea is discovered. These ventures do so because resources, partners and markets are scarce and dispersed globally. The authors see an importance to distinguish between tech ventures and low-tech, this is because they are subject to very different influences and pressure from the global market. The conceptual framework used by the authors is based on the same entrepreneurial processes that are used within this research.

\subsection{Projects}

The general definition of "project" by Dictionary.com is described as i) "something that is contemplated, devised, or planned; plan; scheme", ii) "a large or major undertaking, especially one involving considerable money, personnel, and equipment".

Casson (2007) paper on the discovery of opportunities is central to this thesis. Many of the concepts used in this thesis are extracted from that paper. The paper closely links the concept of opportunity with project, where an opportunity is "essentially a project that would prove beneficial if it were exploited". Some of the key concepts evolve around the idea that resources are allocated between projects rather than activities. Projects involve resources that are committed to a particular use over long period of time. Benefits of generated by a project are realized generally only after costs have been incurred. Complementary projects are grouped together and evaluated as a whole into a project set. Project discovery is analyzed 
as a two-stage process. In the first phase, the entrepreneur identifies one or more fields to focus the search, in the second phase the details of a set of potential projects within a chosen field are examined, appraising their prospects in terms of a number of characteristics. Choosing the field of search can be inward-looking or outward looking approach. In summary, entrepreneurship process "involves three main functions: discovery of an opportunity, procurement of resources for a project, and the realization of benefits through project implementation".

Archer \& Ghasemzasdeh (1999) An integrated framework for project portfolio selection discuss about the definition of project, which can be defined as a complex effort, usually less than three years in duration, made up of inter-related tasks, perform for various organizations, with a well-defined objective, schedule, and budget. A project portfolio is a group of projects that carried out under the sponsorship and/or management of a particular organization.

\subsubsection{Project As Opportunities}

Elfring and Hulsink (2001) - Networks in entrepreneurship: the case of high techtechnology firms. This paper distinguishes three entrepreneurial processes in new venture development; these are the discovery of opportunities, securing resources, and obtaining legitimacy, which are argued by the authors to be important for the survival and performance of the new venture. This process is the framework used within this thesis. It's argued that entrepreneurship is concerned with the discovery and exploitation of profitable opportunities. The next step deals with the ability to acquire resources, where the firm must access, mobilize and deploy resources in order to exploit the opportunities. In the third step, when the entrepreneur embarks on a venture that is innovative, it has to secure legitimacy. Incremental or radical innovation brings different legitimacy challenge. The authors argue about two type of legitimacy, one is cognitive legitimacy, second is socio-political legitimacy. 
Aaboen et al. (2013) argue about three patterns for strategizing as networking for new ventures: exploitation and exploration of similarities, knowledge sharing among customers, and developing relationships with mediating partners.

The first identifies pattern concerning interaction with customers resulting in ideas about how knowledge developed in a relationship. The second interaction pattern concerns development of ideas about how customer relationships can be directly connected to enable customers to benefit from knowledge sharing in their uses of the product. The third pattern concerns the interaction that results in the formation of strategies on how to work through other actors. By mean of the examples, the author discuss how new venture's business development shift from the focus on "what to sell", to "how to sell to", and then to "how to build a position in the network".

Following the concept behind the entrepreneurial processes framework, Song et al. (2008) discuss the success factors in new venture by mean of a meta-analysis. The authors mentioned that amongst the 24 possible factors identified in the literature, 8 are significant for new technology venture: 1) supply chain integration; 2) market scope; 3) firm age; 4) size of founding team; 5) financial resources; 6) founders' marketing experience; 7) founders' industry experience; and 8) existence of patent protection. Most of these significant success factors are used in this research as an evaluation filter for a project space attributes and outcomes. 


\section{Chapter 4 - METHOD}

This chapter describes the method used to produce the deliverables of this research.

\subsection{Approach}

This research is explorative and the object is not to test particular hypotheses but to contribute to a constructive research in the field of high-tech entrepreneurship. Because of the inductive nature of the research, the selection of the cases was not a random processes, it's based on sampling experiments with different well-defined job-to-be-done segment.

A constructive approach (Peffers et all, 2007) was selected for this research particularly for combinations of reasons:

1 - Strong business interest to construct an organization that is global at inception. The research benefits both the stakeholders by producing real business outcomes and deliverables that benefits management theory.

2 - A constructive approach provides a methodology grounded on theory and practice such that the research can be performed on a real work project, where data collection is based on real life experimentation.

\subsection{Unit Of Analysis}

The unit of analysis is a project space, its attributes and outcomes, components, interactions, environment and principles. These attributes include metrics, the type of project space, etc.

For this study, data collected for a project space will summarize the lessons learned from all project probes associated to one project space. 


\subsection{Study Period}

The use cases study period covers from beginning 2013 until March 2014. Data has been collected throughout the entire period.

To limit the scope of the thesis, six (6) project spaces have been used to gather data. Project Probes have been created, managed for each project space. However, it's not fully documented within this thesis to limits extra contents, they are summarized as part of the project space itself.

\subsection{Research Method}

This research follows the Design Research methodology used by McPhee (2012) and Peffers et al. (2007). The "Knowledge Box" concept is from McPhee (2012) performance framework.

The following table summarizes the research methods. 
Table 3 -Research methods

\begin{tabular}{|c|c|}
\hline Phases & Steps Followed \\
\hline $\begin{array}{l}\text { 1. Problem Identification } \\
\text { and capture lessons from } \\
\text { theory }\end{array}$ & $\begin{array}{l}\text { - Identify the challenges faced by tech new venture in operating a } \\
\text { global start organization around the innovation engine concept. }\end{array}$ \\
\hline $\begin{array}{l}\text { 2. Obtain a general and } \\
\text { comprehensive } \\
\text { understanding of the topic. }\end{array}$ & $\begin{array}{l}\text { - The second phase of the research resides in two main activities: } \\
\text { i) studying relevant literatures, ii) experimental learning by } \\
\text { creating the Zination Publishing Platform and operating the } \\
\text { platform. } \\
\text { - Understanding of the literature in the following streams: Global } \\
\text { start stream, business ecosystem stream, entrepreneurship } \\
\text { stream, and project stream. }\end{array}$ \\
\hline $\begin{array}{l}\text { 3. Adapt the Innovation } \\
\text { engine and create the } \\
\text { Project Space Framework }\end{array}$ & $\begin{array}{l}\text { - Create the innovation engine for tech new venture by adapting } \\
\text { the "project community" concept into the project space concept } \\
\text { - Define the project space and project probe concept } \\
\text { - Design the project space attributes and outcomes grounded on } \\
\text { theory and practice } \\
\text { - Create the Project Space Framework to help new ventures to } \\
\text { cope with market experimentation for: ii) exploration of } \\
\text { different concrete opportunities, ii) find the right niche while } \\
\text { minimizing resources allocations }\end{array}$ \\
\hline
\end{tabular}

- Implement the design, including the launch of Zination Publishing platform.

- Gather project space and project probes, gather performance-

4. Demonstrate the design work on a real world implementation based data

- Capture lessons learn from operating real world project spaces through each stage of the project space framework into the knowledge box such that it can be used as a feedback loop to help in the evaluation and creation of other project spaces. 
- Discuss performance data resulted from operating the

5.Show theoretical connections and research contribution of the proposed concept

6. Examine the scope of applicability of the research innovation and the project space framework

- Connecting research to theory

- Design propositions to help entrepreneurs in decision making

- Discussed how the methodology and design principles can be applied to other type of web-based new ventures.

\subsubsection{Phase 1 - Defining the problem}

The research problem presents itself to all new ventures that are struggling to bring their innovation to the marketplace. Many new ventures fail within the first three years (Statistics Canada, 2000), many others fail earlier. Many factors impacts the failure rate:

- Competitive landscape: globalization brings new opportunities and threats;

- Market Scope: finding the right market fit to serve and monetize such that it can help new venture to sustain.

The innovation engine concept provides good guidance for new venture to improve that odd, however more evidences are required to support theory, in particular we don't know how to create and operate the innovation engine for web-based startup, additionally we don't how to manage the project community in the for-profit context.

With the help of the TIM faculty and other business partners' inputs, we synthesized the problem into the following research question: How can new venture design and operate an organization around the innovation engine concept. More specifically, this research objective is to explore how tech new venture can create an innovation engine to construct a web-based organization, while using a framework that helps to 
better find the proper market fit, reducing risk of over investment into nonperforming market.

\subsubsection{Phase 2 - Understanding of the topic}

The second phase of the research resides in two main activities: i) studying relevant literatures, ii) experimental learning by creating the Zination Publishing Platform and operating the platform.

The most relevant literatures contributing to the understanding of the topic are: Global start stream, business ecosystem stream, entrepreneurship stream, and project stream.

\subsubsection{Phase 3 -Design the Project Space Framework}

The approach includes:

1. Creation of new constructs for coping with opportunity discovery; and

2. Identifying their attributes to better gauge market fit.

The results-based performance management framework from McPhee (2012) inspired this research in the creation of the project space framework.

\subsubsection{Phase 4 - Implementing the Solution and Gathering Data}

Project space attributes are gathered based on the review from the founding team member based on the perception and results from operating the project spaces. A scale of 1 to 10 is assigned to each attribute. Project space outcomes are collected during and at the end of the research period, based on the business experimentation 
for each project space. Data is collected based on the results from operating these project spaces on real world project probes results.

The following table illustrates the template for data collection (of the outcomes) during the research period.

Table 4 depicts the template for Data Collection for the Innovation Engine

Component Data Definition

\section{Project Space}

Number and type of project space created and operated

Project Space Attributes collected

Project Space Outcomes

Project Evaluation

\section{Organization}

Shareholders

Board of advisors

Organization

Staffs employed and generated

\section{Business Ecosystem}

End users

Customers

Partners

Supply chain

\section{Platform}

IP created while operating the innovation engine and its project space Infrastructure outputs

Software elements created

Common Assets created within the innovation engine

\subsubsection{Phase 5 - Showing the theoretical connections and research contribution}


In this phase, we demonstrate the connections between this constructive research and details the research contributions.

\subsubsection{Phase 6 - Examining the Scope of applicability of the Solution}

The cases studies for the project space are around five niched markets. These markets are selected for being the most appropriate market offer best served by Zination value proposition. 


\section{Chapter 5 - Results}

This chapter documents the results obtained from the research new constructs and results from operating a real-world new venture based on the Zination Platform.

\subsection{Zination Platform}

Zination is a social publishing platform that allows end users to create, beautify and publish their online contents. The platform has been created to be scalable, leveraging the viral product design principles. The core value proposition of the platform is around real-time beautification engine. The Zination Engine takes welldefined content, applies its beautification "Zine filters" and generates an html5 online magazine (called Zine) that can we shared to other web platform and is search engine friendly. All Zines generated by the platform are hosted in the cloud; alternatively it can be exported for offline viewing if required.

Depending on which market the Zination Platform is positioned; the offering is facing direct and indirect competitors. In all project spaces explored during this research, customer needs are meet with some degree by competitors; nevertheless Zination offering has very strong differentiators such that it can serve better the market niched at a more affordable cost, while drastically allowing time saving for its targeted customers.

This research captures the results from operating this real world platform in its early stage of development to experiment and validate validity of the new framework. 
From early result, it showcases the platform involving many actors including consumers (in the thousand), small and medium enterprises (less than twenty) and a few partners (mostly other platform providers).

Interactions of the platform with other partners during the research period were around the study of the method to integrate partner's system with the Zination Publishing Engine by mean of Web API.

\subsection{Scope of the research}

To limit the scope of the thesis, the report limits mainly to the project space component of the innovation engine.

\subsection{Research New Constructs and Their Attributes}

The approach, developed to design a solution to the research problem, combines the innovation engine proposed by Bailetti (2013) with the entrepreneurial processes. The approach examines further into the "Community Project" component of the innovation engine to adapt it for a "for profit" organization, while providing the benefits to allow new ventures to better test for market fit, helping new venture to increase their chance of survival.

The approach includes:

1. Creation of the Project Space concept

2. Creation of the Project Probe concept

3. Development of the Project Space Framework concept with its phases and elements

4. Identification of the Project Space attributes and outcomes grounded on theory and experience 
5. Identification of Project Probe attributes and outcomes based on experience

6. Creation of the Project Space Evaluation Matrix

\subsection{Project Space Definition}

This research is focusing more specifically on the Project Space component. The size and importance put forth for each component depends on the entrepreneur intend and nature of the business. In the context of a Global Start organization building, the Project Space component is viewed as the most relevant and should be the main focus point. This component drives the size, interactions, creation, and process for the management of the other components of the innovation engine. As the organization grows in size and maturity, other components will shape differently to take into account the evolution of the organization. When a Global Start is still at its very infancy, the platform component is the focus point. As it mature, the business ecosystem is taking the center stage.

\subsubsection{Definition of Project Probe}

A project is defined in some literature as a "large or major undertaking, especially one involving considerable money, personnel, and equipment" and time, (Dictionary.com). Another definition, "a project can be defined as a complex effort, usually less than three years, made up of inter-related tasks, performed by various organizations with a well-defined objective, schedule and budget", Archer \& Ghasemzadeh (1999).

Within this research, a project is an undertaking with a well-defined objective, schedule, budget and resources allocated and committed by the organization to serve a market need.

Furthermore, we follow Casson (2007) concept of project as an opportunity that has found to be beneficial and is exploited. It's an exploited opportunity to generate goods and services for future profitability. Stocks of resources are committed over a 
period of time, requiring funding and project management. Within the research, an opportunity indicator to capture those that can continue further or must be stopped also characterizes each project. In the context of a small startup, resources are very limited; hence entrepreneur has to take rapid action to move away from underperform project.

A set of project assembled together for common denominator is character by Casson (2007) as a project set or project portfolio. In this research, one project portfolio or set is assembled into a project space. The next section provides in more details the definition of project space, which is an extension of a project set concept.

A project probe is a project, part of a project space, used to test for market fit and see how it performs in the market place. A project probe, contrary to a "common" definition of a project, is an opportunity testing mechanism for market fit. Its lifespan tend to be shorter. A project probe becomes a real project when its outcomes and performance are satisfactory for the new venture.

Another way to define a project probe is to conceptualize it to project as opportunity.

\section{Project Probe Attributes}

Source of the Project Attribute: from theory and from experience

Table 5 - Project Probe Attributes

\begin{tabular}{|c|c|c|}
\hline ID & Project Probe Attribute & Description \\
\hline 1 & $\begin{array}{l}\text { Resources Commitment } \\
\text { Level }\end{array}$ & nent to the project \\
\hline 2 & Partner Type & Type of partner involved in the project \\
\hline
\end{tabular}


3 Revenue Type

4 Customer Type

5 Scope

$6 \quad$ Risk

$7 \quad$ Tech uncertainty

$8 \quad$ Cost

$9 \quad$ Benefits

10 Platform Advancement
Direct or indirect revenue from the project Type of customer involved in the project How well the project is scoped out, is it large or narrow scope.

Risk of the project toward the organization Technological uncertainty to be able to succeed in operating the project

Low cost or high cost involved to serve the project

The kind of benefits that can be extracted from a project

The project is contributing to the platform advancement in what form and size of the impact

\section{Project Probe Outcomes}

Table 6 -Project Probe Outcomes

\begin{tabular}{|c|c|c|}
\hline ID & $\begin{array}{l}\text { Project Probe } \\
\text { Outcome }\end{array}$ & Description \\
\hline 1 & Customer Acquisition & \\
\hline 2 & Revenue & Type of revenue generated (service/product) \\
\hline 3 & Space Intelligence & $\begin{array}{l}\text { Lessons learn from the project that cans feed } \\
\text { the understanding of the project space. }\end{array}$ \\
\hline 4 & $\begin{array}{l}\text { Organization } \\
\text { Capability }\end{array}$ & Level of impact on the organization capability \\
\hline 5 & IP & $\begin{array}{l}\text { IP created or not from the operation of the } \\
\text { project }\end{array}$ \\
\hline 6 & Progression Signal & $\begin{array}{l}\text { Indicator if the project is to continue, pending } \\
\text { or stop }\end{array}$ \\
\hline 7 & $\begin{array}{l}\text { Project Creation } \\
\text { Process }\end{array}$ & Knowledge on how to create other project \\
\hline 8 & $\begin{array}{l}\text { Platform } \\
\text { Advancement }\end{array}$ & $\begin{array}{l}\text { The project contribute lowly or highly to the } \\
\text { platform advancement }\end{array}$ \\
\hline 9 & Partner & Partner created or no partnership involved \\
\hline 10 & Good \& Services & $\begin{array}{l}\text { Kind of goods \& services produced from the } \\
\text { project }\end{array}$ \\
\hline 11 & Cost & $\begin{array}{l}\text { Cost to operate the project, low, medium or } \\
\text { high. }\end{array}$ \\
\hline
\end{tabular}




\subsubsection{Definition of Project Space}

According to Casson \& Wadeson (2007) "the set of potential projects, from which opportunities are drawn is always very large, and so it's important for the entrepreneur to choose the right field in which to search". Further, the authors added the success of the entrepreneur could be explained by their good judgment in the choice of search strategies. The authors describe "project set" as grouping complementary projects together and evaluating them as a whole. Conflicting projects are assembled into separate groups with the provision that only one group can be undertaken. This method of organization is to address the complementary aspect.

We concur with Casson \& Wadeson (2007) in the argument for a better search strategy. With this guidance, this research assembles collection of projects together into the concept of Project Space. Similar to Casson \& Wadeson (2007) of project set, a project space additionally includes defined attributes and outcomes relevant to the platform.

A project space comprises of a portfolio of projects, with a well-defined intent, goals, process, inputs and outputs to enable the innovation engine to operate successfully.

A project space is a small instance of an entrepreneurial process designed to tackle one market scope (defined by a job-to-be-done).

A project space is a set of projects, which tackle a common market scope. All projects within a space have a synergy and evolve around handling the same job, opportunity.

A project space concept is instrument for new ventured to experimental and further probe a market by putting one foot down into a market without full commitment 
until stronger evidences are gathered, allowing the new venture to commit further with better knowledge of the market and it performances.

A project space is an experimentation analysis of a market fit by mean of real test of the market with real life involvement of the new venture into a market.

The art for entrepreneur resides than in operating the framework effectively by way of minimizing organizational investment. In new venture saying, it's better to fail fast. In that same mindset, it's better to test the space and gather evidences rapidly to help decide if the space opportunity must be pursued or stopped.

The project space concept is created to better crystallize the seizing of opportunity as described by Casson (2007), a project is a realization of an opportunity. A project space is a seized opportunity with further investment with many tested experimentation probes inserted into the market to verify and validate for market fit.

A project space concept is created to be a better instrument in probing market fit for new ventures. It's designed to minimize the risk in investment and to help the innovation engine to perform better.

\subsubsection{Project Space Attributes}

Project space has many attributes. It can be characterized by the intent of the space. Is the project space objective for $R \& D$ purpose, or is it for customer acquisition so that it can generates revenues for the organization, or is it for exploration of market opportunities.

Project Space attributes are extracted from theory and experience from operating new venture. 
Table 7 -Project Space Attributes

\section{Attributes}

\section{Opportunity Discovery}

Market Scope

Environmental

Dynamism

Competition Intensity

Product Innovation

Revenue Model

\section{Gain Legitimacy}

Marketing Intensity

Risk

Platform Advancement

Synergy

\section{Resources}

Financial resources

Size of team

Supply chain

integration

R\&D Investment

\section{Selected} References

\section{Definitions}

Evaluation Results

"Variety in customers and customer segments, their geographic range, and the number of products."

"High pace of changes in the firm's external environment".

"Strength of inter-firm competition within an industry".

"Level of innovation of the offered product relative to the industry".

Model to bring revenue to the firm
"Extent to which a firm is pursuing a strategy based on unique marketing efforts."

Perceived level of risk

Type of contribution to the platform advancement.

Level of synergy with the current platform capabilities.

"Level of financial assets of the firm."

Degree of resources investment

Song et al. (2008)

from the firm to tackle the project space.

"Firm's cooperation across different levels of the value-added chain (e.g., suppliers, distribution channel agents, or customers)."

"Intensity of the firm's investment in internal R\&D activities"
Scale 1 to 10 . Better scope is 10 .

Low change has a value of 10 .

Low intensity has value of 10 . 10 means good production innovation. Good revenue model is 10 .

Low marketing intensity is 10 .

Low risk is 10 , high risk is 0 .

Good platform advancement is 10 .

Good synergy is marked with 10 .

Sufficient financial resources are 10.

Small team size is 10 .

Marked as 10 for a good supply chain.

10 requires small R\&D. 
Current project space attributes are organized to map with the entrepreneurial processes phases.

\subsection{Opportunity Discovery Related Attributes}

\section{Market Scope}

In the opportunity discovery related attributes, a project space is characterized by its market scope. The space is further characterized by specific job to be done (Christensen et al., 2007), market, features and benefits.

\section{Environmental Dynamism}

Additionally, it's characterized by the environmental dynamism, is the environment moving at high speed or vey slowly. The pace of innovation is very fast, or is progressing very slowly.

\section{Competition Innovation}

Furthermore, competition intensity provides a gauge of the level of threat, aggressiveness of the offering when entering the market.

\section{Product Innovation}

Additionally, the product innovation characterizes the level of innovation offered by the new venture product relative. The new product can be very disruptive or is an incremental innovation.

\section{Revenues Type (Business Model)}

The revenues type is an attributed from experience, where when taping into a jobto-be done, an organization needs to figure out how to monetize the value proposition. The revenue type can be direct, where consumers pay the organization directly. The revenue type can be indirect; in which case, the revenues come through channel partners. 


\subsection{Gain Legitimacy Related Attributes}

\section{Marketing Intensity}

The marketing intensity is the project space attribute to provide an indicator how much investment is required on the marketing side to ensure the project space can succeed. The more marketing it required, it's an indicator the value proposition is hard to sell. Low intensity is an indicator the product or service can "sell" itself.

\section{Project space risks}

This attribute measures the project space risk on a scale level and on our management team perception of market risk associated to a project space. This attribute is a result from our experiential knowledge in the field. Each project space involves large investment from the organization. Criteria that impact the perception of risk are many. The major one is market risk. This is linked to the concept of jobto-be-done provided by the platform. When moving into a new project space, is the market big enough, can we achieve our business objectives by moving one project space. The second one is adoption risk. Some project space can be served well, with limited adoption friction. A project space where the adoption friction is higher is riskier for the organization.

\section{Platform Advancement}

This attribute is for the innovation engine system-results outcomes; it's again an indicator to level of IP potential for the organization. IP Potential attribute that is very low is an indicator that the result from operating a space is not helping in creating new IP for the organization. The other platform advancements outcomes are infrastructure, software, protocols, and common assets.

\section{Synergy}


The synergy attribute characterizes the project space synergy relative to other project spaces and relative to the platform. If a project space has strong synergy, many of the common assets are used, similar technology components are used, and similar software components are used. Strong synergy helps reduce the required resources to support a project space.

\subsection{Secure Resources Attributes}

\section{Financial Resource}

This attribute characterizes the level of financial resources required to operate the project space.

\section{Size of team}

A good level of indicator for the number of human resources required. The bigger the size of the team, the bigger risk it's for operating the project space.

\section{Supply Chain integration}

This attribute characterizes the level of supply chain integration involved. When suppliers, partners are involved, it allows the project space to participate in an established market.

\section{$R \& D$ Investment}

This attribute characterizes the level of research and development required to ensure the project space can progress or succeed. It is an indicator to the level of investment in $\mathrm{R} \& \mathrm{D}$.

\subsubsection{Project Space Outcomes}

Part of the process for the management of the innovation engine resides in well managing the project space outcomes. Core outcome for a project space is a signal 
to further invest in the project space opportunity. Other outcomes are important but are relevant only if the space is to be pursued in the short and long term.

\section{Table 8 -Project Space Outcomes}

\begin{tabular}{|c|c|c|}
\hline Outcomes & Definitions & References \\
\hline Customer acquisition & $\begin{array}{l}\text { Number of customers or project } \\
\text { customers acquisition }\end{array}$ & Team experience \\
\hline Revenues & $\begin{array}{l}\text { Revenues or realistic projected } \\
\text { revenues }\end{array}$ & Team experience \\
\hline Market Intelligence & $\begin{array}{l}\text { Lessons learn on the market analysis } \\
\text { with real market probing. }\end{array}$ & Team experience \\
\hline Organization Capability & $\begin{array}{l}\text { Organization Capability gathered from } \\
\text { probing the project space. }\end{array}$ & Bailetti (2013) \\
\hline IP & $\begin{array}{l}\text { Intellectual properties generated by } \\
\text { operating the project probe. }\end{array}$ & Bailetti (2013) \\
\hline $\begin{array}{l}\text { Project Space Creation } \\
\text { Process }\end{array}$ & Project Space Creation Process & Team experience \\
\hline $\begin{array}{l}\text { Platform Advancement } \\
\text { outputs }\end{array}$ & $\begin{array}{l}\text { Platform Advancement outputs, } \\
\text { desired system-level results. }\end{array}$ & Bailetti (2013) \\
\hline Integrations & $\begin{array}{l}\text { Partner Acquisition and or number of } \\
\text { integrations into the supply chain. }\end{array}$ & Song et al. (2008) \\
\hline Cost & Cost level for operating the space. & Team experience \\
\hline Market fit & $\begin{array}{l}\text { The new value proposition if changed } \\
\text { while experimenting with the project } \\
\text { space. }\end{array}$ & Team experience \\
\hline Revenue Model & $\begin{array}{l}\text { Actual revenue model adopted for the } \\
\text { project space. }\end{array}$ & Team experience \\
\hline
\end{tabular}

\section{Formula to determine the attribute criterion and the outcomes criterion}

The following is the formula to calculate the attributes criterion and outcomes criterion from each project space.

$$
\begin{aligned}
& \text { Attribute Criterion }=\left(\frac{\sum(\text { attributes })}{\text { Total attributes count }}\right) * 100 \\
& \text { Outcome Criterion }=\left(\frac{\left.\sum \text { (outcomes }\right)}{\text { Total outcomes count }}\right) * 100
\end{aligned}
$$


Where:

Total Attributes Count: 130

Total Outcomes Count: 110

The Attributes Criterion describes attributes of a project space. It evaluation is performed early within the existence of a project space lifespan. The outcomes criterion is evaluated at the end of each entrepreneurial process (opportunity discovery, secure resource, gain legitimacy).

\subsection{Criterion of Profitability}

The Project Space score provides some criterion indicator of profitability for the new venture. A normalized score of $100 \%$ is a strong signal of profitability, a good indicator to pursue further experimentation and investment. A score of $0 \%$ is a signal to dissuade from further investment.

\section{Adapted research framework from Elfring (2004) for Project Space}

Table 9 -Three entrepreneurial processes and its activities

\begin{tabular}{lll}
\hline Processes & Activities & Definitions \\
\hline Opportunity Discovery & Opportunity Identification \\
& $\begin{array}{l}\text { Opportunity Development } \\
\text { Opportunity Evaluation }\end{array}$ & \\
Secure Resources & \\
& Access to resources \\
& Mobilize Resources
\end{tabular}


Deploy Resources

\section{Gain Legitimacy}

Gain Cognitive Legitimacy

Gain social-political legitimacy

This search outlines a model, which attempts to clarify the stages of project space management as part of the innovation engine framework.

This model is an adaptation of the Elfring (2003) paper on entrepreneurial processes. These three processes intervene as part of the processes that regulate the key performance outcomes of the entrepreneurial processes.

Main focus of entrepreneurship is with respect to discovery and exploitation of profitable opportunity. The first process is the discovery of opportunities. The second process deals with the organization ability to acquire resources. The third process involves gaining legitimacy.

\subsection{Opportunity Discovery}

The discovery of opportunity is the foremost important first process of the project space management process. This process comprises of the opportunity identification, opportunity development and opportunity evaluation. Opportunity identification is the stage at which new ventures exploring niched opportunity, well-defined job to be done, problem solving value creation and value sought. This stage is the starting point to create a list of opportunities to tackle. Opportunity development is the next phase of the process to further analyses the opportunity size, competitor's analysis, and market analysis. Third stage of this process is the evaluation of the opportunity, as gate process that can gauge on the opportunity adoption, a trigger to move to the next entrepreneurial process. 
Opportunity that can't be handled by the new venture is pushed to a database for future review.

\subsection{Secure Resources}

Secure resource is the second most important entrepreneurial process as part of the project space management framework. New venture rarely possesses all the resources required to seize an opportunity. Gaining access to resources is a crucial task. Mobilize the organization to secure resource and commitment is the second phase. Thirdly, organization decides to deploy resources in form of personnel, equipment, time and funds to fully tackle the opportunity. In any entrepreneurial processes, the organization can decide to re-evaluate the outcome and progress and can decide to signal a stop or a good ahead with an opportunity and or project space. For new venture where resource is a precious asset, some opportunities are discarded simply for the lack of available resource at the current time. Putting the opportunity into a database for future review is a method to enable review of opportunity when resources are again available.

\subsection{Gain Legitimacy}

The third entrepreneurial process, integral part of the project space management, contributes to the success of a new venture in the way to opens possibilities to gain legitimacy. Gaining legitimacy is imperative for new venture starting something that is innovative. Established organization has an edge, for new venture failure is a very high probability. Understanding the nature of the new concept is referred to Suchman (1995) as cognitive legitimacy. Overcoming this legitimacy barrier can be achieved by mean of mobilizing actors like competitors, distributors, and universities to create partnerships in order to gain wider understanding of the innovation. The second legitimacy is labeled as socio-political legitimacy, referring 
to how key stakeholders accept the startup as appropriate and conforming to accepted rules and standards.

Each project space is evaluated with respect to its phase, signal for further progress, discarding or future review and the outcomes. The matrix provides a good view of the state of each project space and provides a feedbacks and indicator for the status of each.

\subsubsection{Project Space Creation Process}

The Creation of project space follows a simple process of evaluating a new opportunity against the project space attributes evaluation template. An evaluation result over $50 \%$ provides a good indicator of opportunity profitability and is an indicator to pursue the opportunity. This process is illustrated in figure 5 as part of the screening process in Phase 1. As stated in Casson \& Wadeson (2007), "the key to entrepreneurial success is to possess sufficient judgment to recognize true opportunities and screen out false ones". Hence, this phase is crucial for new ventures.

Table 10 -Project Space Evaluation table based outcomes vs. entrepreneurial processes phases

\begin{tabular}{lccc}
\hline \multicolumn{1}{c}{ Outcomes vs. Phase } & $\begin{array}{c}\text { Opportunity } \\
\text { Discovery }\end{array}$ & $\begin{array}{c}\text { Secure } \\
\text { Resources }\end{array}$ & $\begin{array}{c}\text { Gain } \\
\text { Legitimacy }\end{array}$ \\
\hline Customer acquisition & & \\
Revenues & & \\
Market Intelligence & & \\
Organization Capability & & \\
IP & & \\
Project Space Creation & & \\
Process & & \\
Platform Advancement & & \\
outputs
\end{tabular}


Integrations

Cost

Market fit

Revenue Model

\subsubsection{Interaction Patterns for new ventures}

During the first phase of the entrepreneur process, Aaboen et al (2013) describe in a meaningful manner the three patterns of interaction for new ventures.

The three patterns are the following:

1 - Exploration and Exploitation

2 - Knowledge sharing among

3 - Developing relationships with mediating partners

The first interaction pattern concerns the interaction with customers, or potential customers, with the objective to gather knowledge on how to develop relationship that can be used to develop new features in a product or to gain new customers.

The second interaction pattern concerns the interaction with customers and how the knowledge sharing of their use benefits other customers.

The third interaction pattern concerns the formation strategies to work through other actors. This method relies on mediation to gain access to additional customers.

Table 11 summarizes the keys characteristics and relationship of the actors with respect to a project space

\begin{tabular}{|c|c|c|}
\hline $\begin{array}{c}\text { Project \& } \\
\text { Project Space }\end{array}$ & Actor Description & $\begin{array}{c}\text { Key Characteristics And } \\
\text { Relationship }\end{array}$ \\
\hline
\end{tabular}




\begin{tabular}{|l|l|l|}
\hline & & \\
\hline & & \\
\hline & & \\
\hline
\end{tabular}

For data collection, Table M provide a summarize method to capture each project and each project spaces, provide a description of each component, their characteristics and the relationship to other project or project space.

\subsubsection{Project Space Framework - A framework for new market fit experimentation}

The project space framework is grounded on theory, adapted from the entrepreneurial processes, with additions to take into account the decision making element, the project probe creation and operation, and the lessons learn element such that it helps new venture to iterate and experiment with others market fit validation. 


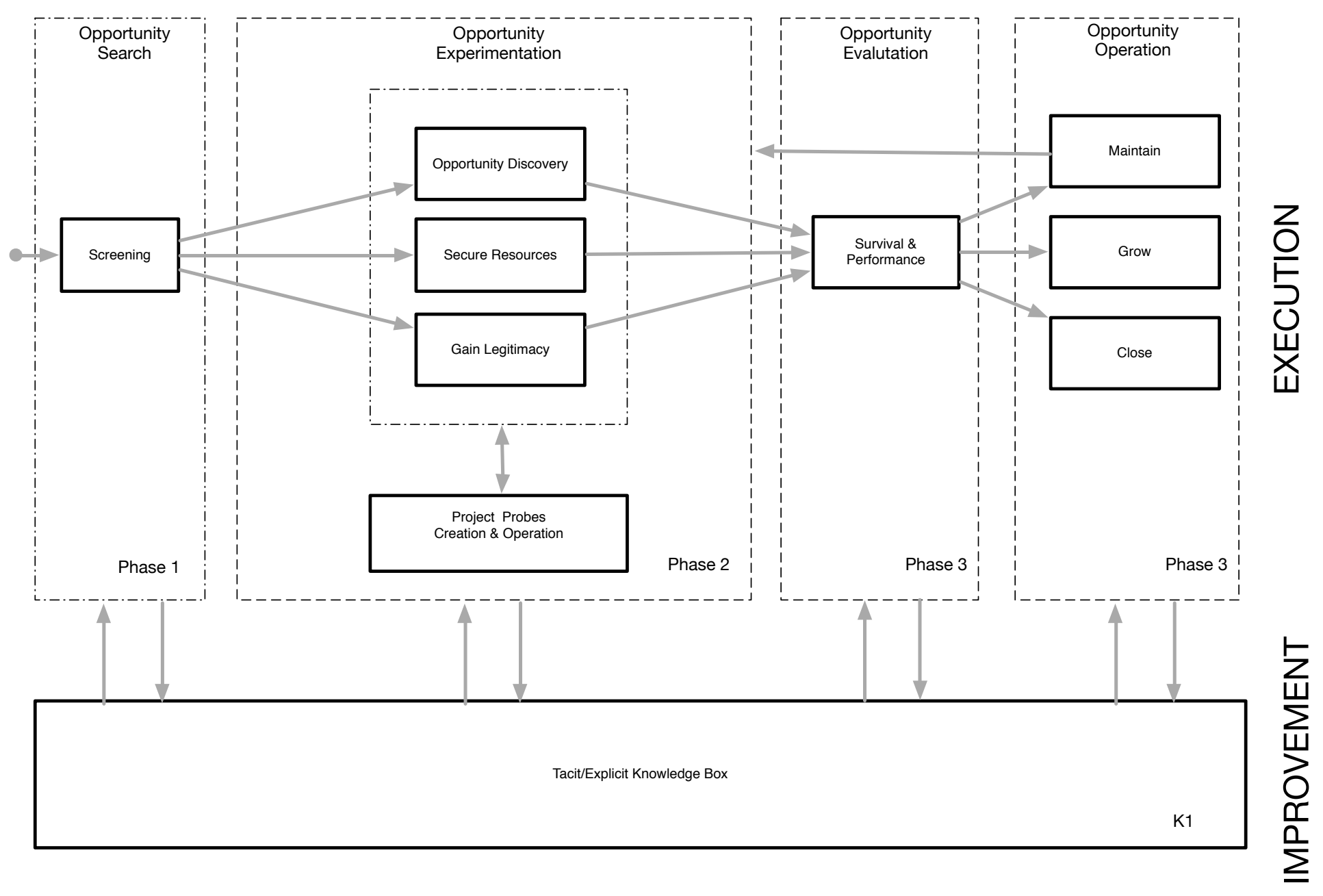

Figure 5 - Project Space Framework

This research attempts to organize the many variables that have been used in the literature to describe entrepreneurial processes and their venture into a comprehensive process framework. Far from being reductive, this new view of the entrepreneurial processes should provide valuable insights into the process of new venture exploitation by demonstrating it to be a multi dimensions phenomenon.

This framework is an attempt to combine the three entrepreneurial processes into a more specific context of the innovation engine framework, to enable new venture to experiment the market, to identify the right market fit, one with the most optimal result, to help the survival of the new venture. 
The framework enables us to examine systematically how the entrepreneurial processes can help identify and operate the most performing job-to-be-done target market and to support the operation of the innovation engine.

The framework consists of five elements: opportunity search, opportunity experimentation, opportunity evaluation, opportunity operation and innovation engine lessons learn.

The arrow between the elements illustrates the interactions between elements of the framework.

\subsubsection{Opportunity Search}

Searching for new opportunity and exploiting one is in the DNA of entrepreneurs. As described by Casson (2007), the search can be inward looking or outward looking. This phase purpose is specifically to screen incoming opportunities and select the ones that can be experimented handle by the organization. Some of the screening criteria are established to help in that process.

This phase represents the first filtering phase of the framework.

\subsubsection{Opportunity Experimentation}

Analysis of a market fit based on market research has it values. For new venture, relying purely on the market analysis to commit entire new venture resources can be costly. Furthermore, a failure to properly understand the market can bring a new venture to its mortality. The Opportunity experimentation phase is a mechanism provided by the framework to test the market fit in real market experimentation. 
Creating a number of project probes within a space enables new venture to test for market fit and gather data for further analysis.

A project probe is a project (Casson \& Wadeson, 2007) that has been allocated to tap into an opportunity, with the initial objective to test a market (lightweight project), knowing it can be stopped at any point, rapidly, to minimize investment in time and resources. A simple customer interview can be viewed as a project probe. An entire dedicated product development can also be viewed as a project probe, understanding it's designed to test a new market.

Customer acquisitions, adoption levels, revenues model, etc. can be used to evaluate the performance of the project space. Relying purely on the interview to make a positive decision can be risky, however the interview can be used to rapidly discard project space value where it's evident that it does not fit the market needs. The more project probes, the better to evaluate the project space. However, each probe can be very expensive for a new venture, depending on the project probe investment. Hence, optimizing usage of probes becomes one major undertaking that must be properly handled by new venture.

This phase is the most complex element of the framework. Optimizing this phase allows new venture to improve its performance.

Opportunity discovery can be further break down into opportunity identification, opportunity, opportunity development and evaluation. The output of this element signals the project space to secure resources and launch the creation of a number of project probes. Within each element of this phase, the project space can trigger an evaluation and provide signals to how the project space should progress further. While trying to project space legitimacy, again more project probes can be created to support or bring further evidences or supporting arguments for the livelihood of the project space. 


\subsubsection{Opportunity Evaluation}

Opportunity evaluation phase is one critical phase within the framework to perform an evaluation of the progress of the market probes and to terminate experimentation as rapidly as possible. Outcomes from experimentations are analyzed and processed to support the decision making in terminating, maintaining or growing a project space.

This phase encapsulates the second filtering phase of the framework.

\subsubsection{Opportunity Exploitation}

The last phase of the project space framework is in exploitation of the opportunity. An opportunity that is not performing well can be closed down or maintained for further experimentation. A project space that is to be maintained is brought back into the experimentation phase to review or to bring additional probes so that the organization can make a better decision.

\subsubsection{Lessons Learn Component}

The lessons learn element is comprising of outcomes from each phase and a database of lessons learned from tackling a project space and progressing its along the four phases.

\subsubsection{Project Space Interactions}

As illustrated in Figure 5, opportunities are input into phase 1 for screening. The most challenging task from new venture is to screen the proper opportunity and to select the ones that can be pursued and has the most chance for the new venture to succeed. The output of the screening process is moved to the next phase for 
experimentation. It's important for new venture to properly perform this filtering process such that it's not missing or wrongly discarding profitable opportunities.

As the opportunity moves for experimentation phase, to the opportunity discovery, to opportunity development, evaluation takes place at each stage. The output from the experimentation is passed on to the evaluation phase, which captures data and data processing from the experimentation. After data is processed, the outcome is passed to the last phase, which analyze the data and make the decision to grow, maintain or close a project space.

Within each phase, lessons learn (described in section 5.11) gathered to help guide the organization to improve its decision making and to improve its efficiency in managing project space and the innovation engine in general.

In essence, each project is a probe into the market place to experiment and gather data on relevancy of a market niche.

\subsection{Data from Operating the Innovation Engine Model}

\section{Project Spaces Case Studies}

Table 12 -Project Space Case Studies

\begin{tabular}{|c|c|c|}
\hline Project Probes & Probes descriptions & Key characteristics \\
\hline \multicolumn{3}{|l|}{ E-Commerce } \\
\hline $\begin{array}{l}\text { PlatformProvider_A } \\
\text { (P1) }\end{array}$ & $\begin{array}{l}\text { A small e-commerce platform } \\
\text { provider (Oct 2013-April 2014). }\end{array}$ & $\begin{array}{l}\text { Small closed partnership established by } \\
\text { known relationship where integration } \\
\text { brings benefits to both. }\end{array}$ \\
\hline Shopify (P2) & $\begin{array}{l}\text { A medium sized well } \\
\text { established fast growing cloud- } \\
\text { based e-commerce platform } \\
\text { provider (Dec 2013-April } \\
\text { 2014). }\end{array}$ & $\begin{array}{l}\text { Relationship is established indirectly by } \\
\text { mean of the app store enabling } \\
\text { integration into the supply chain. }\end{array}$ \\
\hline
\end{tabular}




$\begin{array}{cl}\text { Magento (P3) } & \begin{array}{l}\text { A dominant e-commerce } \\ \text { platform provider (March } \\ \text { 2014) } \\ \text { A specialized bicycles store } \\ \text { (Nov 2013) } \\ \text { eStore_A (P4) }\end{array} \\ \begin{array}{l}\text { A specialized house furniture's } \\ \text { sore (Nov 2013) } \\ \text { A specialized handcrafted } \\ \text { eStore_B(P5) }\end{array} & \begin{array}{l}\text { online market place (March } \\ \text { 2014). }\end{array} \\ \text { Etsy (P6) } & \end{array}$

Online Marketing Space

SME_A

SME_B

SME_C

SME_D

\section{Events Space}

GEW

Eventbrite

\section{Real Estate}

CREA

\section{Generic Integration}

GenPlatform_A

GenPlateform_B

GenPlateform_C
A startup in providing clinical event management product and service (Nov 2013) A wireless merchant mobiles solution provider (October 2013)

An artisan shop in designing outdoor furniture (April 2013) A retail shop for outstanding olive oil (June 2013)

A non-for-profit organization (November 2013)

A event management platform (September 2013)

A real estate association (July 2013)

A collaborative business intelligence solution provider (Jan 2013).

A innovative startup in providing the next classified (June 2013)

An AI engine for reputation monitoring (Nov 2013)
Platform

Customer

Customer

Platform

Project Space

Customer

Customer

Customer

Customer

A non-for profit organization, helping new ventures. Using the offering to capture important events and push contents to the network.

Platform enabling businesses to publish events.

An association that is the center stage for all real estate partners in Canada.

New venture with founders with long time experience in building innovative BI product. Market well defined, job to be done well defined, in the customer acquisition phase. Reached the gain legitimacy phase.

New player, new venture, well-defined market, pursue partnership to expand and get funding. Still at the discovery phase.

Well-defined job to be done, early stage, still pursuing market identification and customer acquisition. Still at the 
Research and development projects to probe other

R\&D Space possible profitable

opportunities (Jan 2013-Nov

2013). discovery phase.

Source of new ideas and inventions.

\subsection{E-Commerce Project Space}

The e-Commerce market is a well-established market that has many incumbents, many players, and partners. The ecosystem is very well established and has very strong players well positioned.

The job to be done by the Zination platform is to help online storeowners to create beautiful online brochures and organize them to better presents the store products offering. The intent is to indirectly help leads and generates more sales.

Although the E-Commerce Project Space is a very large market. The market scope of the project space studied is small and very precise. The market scope is in providing additional functionalities to current e-Commerce platform players.

\section{Attributes}

The following table describes the E-Commerce Space attributes results (refer to the template from table 7).

\section{Table 13 -Evaluation of E-Commerce Space}

\begin{tabular}{llc}
\hline Attributes & Descriptions & Evaluation Results \\
\hline Opportunity Discovery & Job-to-be-done is well defined. & $10 / 10$ \\
Market Scope & $\begin{array}{l}\text { Change is not very high, but can } \\
\text { Environmental }\end{array}$ & $10 / 10$ \\
Dynamism & $\begin{array}{l}\text { Compelerate. } \\
\text { Competition is low, not well }\end{array}$ & $7 / 10$
\end{tabular}


Product Innovation

Revenue Model

Subscription based with free trial.

$10 / 10$

\section{Gain Legitimacy}

Marketing Intensity

Risk

Platform Advancement

Synergy

\section{Resources}

Financial resources

Size of team

Supply chain

integration

R\&D Investment
With the help of well-established ecosystem, marketing intensity is low and uses the ecosystem as a marketing $8 / 10$ support platform.

Risk level is low

$8 / 10$

Degree of platform advancement is very high.

$8 / 10$

Strong synergy with the current

platform. $90 \%$ of the current platform is re-used.
Small

Minimal resources on the development.

Well-established supply chain integration by mean of the app store.

Small R\&D investment.
$10 / 10$

$10 / 10$

$10 / 10$

$10 / 10$

Criterion of profitability from the project space attributes (formula in section 5.4.2):

$91.5 \%$

\section{Probes}

Six (6) probes have been analyzed and interacted with. Half of the project probes are with platform partners. The other half is with direct customers interactions.

\section{Outcomes}

The following table illustrates evaluation the of the e-commerce space outcomes (refer to table 8 for the template). 
Table 14 Evaluation of e-Commerce outcomes

\begin{tabular}{|c|c|c|}
\hline Outcomes & Description & Evaluation Results \\
\hline Customer acquisition & $\begin{array}{l}\text { Expected to attain } 500 \text { customers } \\
\text { within current year, already have many } \\
\text { direct customer intention agreement. }\end{array}$ & $8 / 10$ \\
\hline Revenues & $\begin{array}{l}\text { Project revenues are sufficient to } \\
\text { support the organization at it early } \\
\text { stage. }\end{array}$ & $9 / 10$ \\
\hline Market Intelligence & $\begin{array}{l}\text { Lessons learn on the market analysis } \\
\text { Good market understanding by } \\
\text { interaction with well-established } \\
\text { players and serving real customers } \\
\text { with real feedbacks. }\end{array}$ & $10 / 10$ \\
\hline Organization Capability & $\begin{array}{l}\text { Strong improvement to the } \\
\text { management and } R \& D \text { team to gather } \\
\text { explicit and tacit knowledge. }\end{array}$ & $10 / 10$ \\
\hline IP & $\begin{array}{l}\text { Medium IP resulted from operating } \\
\text { this space. }\end{array}$ & $6 / 10$ \\
\hline $\begin{array}{l}\text { Project Space Creation } \\
\text { Process }\end{array}$ & $\begin{array}{l}\text { Project creation process was easy, well } \\
\text { fined-tuned, with criterion of } \\
\text { profitability close to } 91 \% \text {. }\end{array}$ & $10 / 10$ \\
\hline $\begin{array}{l}\text { Platform Advancement } \\
\text { outputs }\end{array}$ & Platform advancement is very strong & $10 / 10$ \\
\hline Integrations & $\begin{array}{l}\text { Partner Acquisition and or number of } \\
\text { integrations into the supply chain. }\end{array}$ & $10 / 10$ \\
\hline Cost & $\begin{array}{l}\text { Cost for operating the space is } \\
\text { intermediate. }\end{array}$ & $8 / 10$ \\
\hline Market fit & $\begin{array}{l}\text { Very well market fit, simple value } \\
\text { proposition, established competitors } \\
\text { allow to better understand the market } \\
\text { fit. }\end{array}$ & $9 / 10$ \\
\hline Revenue Model & $\begin{array}{l}\text { Good revenue model, supported by } \\
\text { proven model offered by established } \\
\text { competitors. }\end{array}$ & $9 / 10$ \\
\hline
\end{tabular}

Criterion of profitability from the outcomes (formula in section 5.4.2): 90\% 


\section{e-Commerce Evaluation Matrix}

The following table depicts the Evaluation Matrix Results from operating the project space (refer to table 10 for the template).

Table 15 -Phase Outcomes evaluation for e-Commerce space

\begin{tabular}{|c|c|c|c|}
\hline Outcomes vs. Phase & $\begin{array}{c}\text { Opportunity } \\
\text { Discovery }\end{array}$ & $\begin{array}{c}\text { Secure } \\
\text { Resources }\end{array}$ & Gain Legitimacy \\
\hline Customer acquisition & $\mathrm{x}$ & $\mathrm{X}$ & \\
\hline Revenues & $\mathrm{x}$ & $\mathrm{X}$ & \\
\hline Market Intelligence & $\mathrm{x}$ & $\mathrm{X}$ & \\
\hline Organization Capability & $\mathrm{x}$ & $\mathrm{X}$ & \\
\hline IP & $\mathrm{X}$ & $\mathrm{x}$ & \\
\hline Creation Process & $\mathrm{X}$ & $\mathrm{X}$ & \\
\hline $\begin{array}{l}\text { Platform Advancement } \\
\text { outputs }\end{array}$ & $\mathrm{X}$ & $\mathrm{X}$ & \\
\hline Integrations & $\mathrm{X}$ & $\mathrm{X}$ & $\mathrm{X}$ \\
\hline Cost & $\mathrm{X}$ & $\mathrm{X}$ & \\
\hline Market fit & $\mathrm{X}$ & $\mathrm{x}$ & $\mathrm{X}$ \\
\hline Revenue Model & $\mathrm{X}$ & & \\
\hline
\end{tabular}

Project space progress up to all three entrepreneurial processes.

While operating this project space, all the outcomes defined by this research were possible during the first phase (opportunity discovery) from a number of project probes. The revenue model was determined immediately during phase 1. Integration cost and market fit continue to be learned until phase 3 while trying to gain legitimacy.

The criterion for profitability determination was simple and straightforward. 


\subsection{Online Marketing Project Space}

The online marketing is another big market with well-established players. Most of the players are either in the CMS market, or are social content platforms.

\section{Attributes}

The following table depicts the Online Marketing Project Space Attributes Results.

Table 16 -Project Space attributes evaluation for online marketing space

\begin{tabular}{|c|c|c|}
\hline Attributes & Descriptions & Evaluation Results \\
\hline \multicolumn{3}{|l|}{ Opportunity Discovery } \\
\hline Market Scope & Job-to-be-done is very large. & $5 / 10$ \\
\hline $\begin{array}{l}\text { Environmental } \\
\text { Dynamism }\end{array}$ & Change is very rapid. & $5 / 10$ \\
\hline Competition Intensity & Very high. & $4 / 10$ \\
\hline Product Innovation & Very high & $8 / 10$ \\
\hline Revenue Model & Subscription based with free trial. & $8 / 10$ \\
\hline \multicolumn{3}{|l|}{ Gain Legitimacy } \\
\hline Marketing Intensity & $\begin{array}{l}\text { With the help of well-established } \\
\text { ecosystem, marketing intensity is low } \\
\text { and uses the ecosystem as a marketing } \\
\text { support platform. }\end{array}$ & $5 / 10$ \\
\hline Risk & Risk level is high & $6 / 10$ \\
\hline Platform Advancement & $\begin{array}{l}\text { Degree of platform advancement is } \\
\text { very high. }\end{array}$ & $8 / 10$ \\
\hline Synergy & $\begin{array}{l}\text { Strong synergy with the current } \\
\text { platform. } 90 \% \text { of the current platform } \\
\text { is re-used. }\end{array}$ & $10 / 10$ \\
\hline \multicolumn{3}{|l|}{ Resources } \\
\hline Financial resources & Small & $7 / 10$ \\
\hline Size of team & $\begin{array}{l}\text { Minimal resources on the } \\
\text { development. }\end{array}$ & $7 / 10$ \\
\hline
\end{tabular}


Supply chain

integration

R\&D Investment
Well-established supply chain integration by mean of the app store.

Small R\&D investment.
$2 / 10$

$7 / 10$

Criterion of profitability from the project space attributes: $63 \%$

\section{Probes}

Four (4) probes have been analyzed and interacted with. All probes are with direct customers interactions. Integration with existing supply chain has not been found that worth the integration.

\section{Outcomes}

The following table illustrates of the online marketing space outcomes.

Table 17 -Online Marketing project outcomes evaluation

\begin{tabular}{llc}
\hline \multicolumn{1}{c}{ Outcomes } & \multicolumn{1}{c}{ Description } & Evaluation Res \\
\hline Customer acquisition & $\begin{array}{l}\text { Expected to attain 500 customers } \\
\text { within current year, already have many } \\
\text { direct customer intention agreement. } \\
\text { Project revenues are sufficient to } \\
\text { Revenues }\end{array}$ & $2 / 10$ \\
& $\begin{array}{l}\text { support the organization at it early } \\
\text { stage. }\end{array}$ & $2 / 10$ \\
Lessons learn on the market analysis \\
Market Intelligence & $\begin{array}{l}\text { Good market understanding by } \\
\text { interaction with well-established } \\
\text { players and serving real customers } \\
\text { with real feedbacks. }\end{array}$ & $10 / 10$
\end{tabular}


Strong improvement to the

\begin{tabular}{|c|c|c|}
\hline Organization Capability & $\begin{array}{l}\text { management and R\&D team to gather } \\
\text { explicit and tacit knowledge. }\end{array}$ & $10 / 10$ \\
\hline IP & $\begin{array}{l}\text { Medium IP resulted from operating } \\
\text { this space. }\end{array}$ & $6 / 10$ \\
\hline $\begin{array}{l}\text { Project Space Creation } \\
\text { Process }\end{array}$ & $\begin{array}{l}\text { Project creation process was easy, well } \\
\text { fined-tuned. }\end{array}$ & $10 / 10$ \\
\hline $\begin{array}{l}\text { Platform Advancement } \\
\text { outputs }\end{array}$ & Platform advancement is very strong & $5 / 10$ \\
\hline Integrations & $\begin{array}{l}\text { Partner Acquisition and or number of } \\
\text { integrations into the supply chain. }\end{array}$ & $1 / 10$ \\
\hline Cost & $\begin{array}{l}\text { Cost for operating the space is } \\
\text { intermediate. }\end{array}$ & $8 / 10$ \\
\hline Market fit & $\begin{array}{l}\text { Very well market fit, simple value } \\
\text { proposition, established competitors } \\
\text { allow to better understand the market } \\
\text { fit. }\end{array}$ & $5 / 10$ \\
\hline Revenue Model & $\begin{array}{l}\text { Good revenue model, supported by } \\
\text { proven model offered by established } \\
\text { competitors. }\end{array}$ & $5 / 10$ \\
\hline
\end{tabular}

Criterion of profitability from the outcomes: $58.2 \%$

Online Marketing Evaluation Matrix

The following table illustrates the Online Marketing project space stage evaluation matrix.

Table 18 -Phase evaluation matrix for online marketing project space

\begin{tabular}{lccc}
\hline \multicolumn{1}{c}{ Outcomes vs Phase } & $\begin{array}{c}\text { Opportunity } \\
\text { Discovery }\end{array}$ & $\begin{array}{c}\text { Secure } \\
\text { Resources }\end{array}$ & Gain Legitimacy \\
\hline Customer acquisition & $\mathrm{X}$ & $\mathrm{X}$ & $\mathrm{X}$ \\
Revenues & $\mathrm{X}$ & $\mathrm{X}$ & $\mathrm{X}$ \\
Market Intelligence & $\mathrm{X}$ & $\mathrm{X}$ & $\mathrm{X}$ \\
Organization Capability & $\mathrm{X}$ & $\mathrm{X}$ & $\mathrm{X}$
\end{tabular}




\begin{tabular}{llll} 
IP & X & X & X \\
Creation Process & X & X & X \\
Platform Advancement & X & X & X \\
outputs & & $X$ & $X$ \\
Integrations & X & X & X \\
Cost & X & X & X \\
Market fit & X & X \\
Revenue Model & X & X \\
\hline
\end{tabular}

The project space progressed in all three entrepreneurial processes.

As illustrates by the result evaluation matrix for this project space, all outputs are collected and defined in all phases. The results here are an indicator to how the learning is continual and represents many challenges to the organization. Revenue model changed in all three phases. The criterion for profitability was challenging to determine.

\subsection{Events Project Space}

The job to be done for the event project space is still exploratory. We experimented with many concepts of how to serve this space and how to integrate with established player.

\section{Attributes}

Events Space Attributes Results

Table 19 Project Space attributes evaluation for events management

\begin{tabular}{llr}
\hline Attributes & Descriptions & Evaluation Resu \\
\hline Opportunity Discovery & & \\
Market Scope & Job-to-be-done is well defined, very & $8 / 10$ \\
Environmental & niched. & $5 / 10$
\end{tabular}


Dynamism

Competition Intensity High

$6 / 10$

Product Innovation $\quad$ Very high

$8 / 10$

Revenue Model

$7 / 10$

Gain Legitimacy

\begin{tabular}{|c|c|c|}
\hline Marketing Intensity & $\begin{array}{l}\text { With the help of well-established } \\
\text { ecosystem, marketing intensity is low } \\
\text { and uses the ecosystem as a marketing } \\
\text { support platform. }\end{array}$ & $6 / 10$ \\
\hline Risk & Risk level is low & $7 / 10$ \\
\hline Platform Advancement & $\begin{array}{l}\text { Degree of platform advancement is } \\
\text { very high. }\end{array}$ & $8 / 10$ \\
\hline Synergy & $\begin{array}{l}\text { Strong synergy with the current } \\
\text { platform. } 90 \% \text { of the current platform } \\
\text { is re-used. }\end{array}$ & $5 / 10$ \\
\hline \multicolumn{3}{|l|}{ Resources } \\
\hline Financial resources & Small & $4 / 10$ \\
\hline Size of team & $\begin{array}{l}\text { Minimal resources on the } \\
\text { development. }\end{array}$ & $2 / 10$ \\
\hline $\begin{array}{l}\text { Supply chain } \\
\text { integration }\end{array}$ & $\begin{array}{l}\text { Well-established supply chain } \\
\text { integration by mean of the app store. }\end{array}$ & $2 / 10$ \\
\hline R\&D Investment & Small R\&D investment. & $2 / 10$ \\
\hline
\end{tabular}

Criterion of profitability from the project space attributes: $53.8 \%$

Probes

Two (2) probes have been analyzed and interacted with.

Outcomes

The following table illustrates the Event Space Outcomes

Table 20 Events Project Space outcomes evaluation

\begin{tabular}{ccc}
\hline Outcomes & \multicolumn{1}{c}{ Description } & Evaluation Resu \\
\hline Customer acquisition & $\begin{array}{l}\text { Expected to attain 500 customers } \\
\text { within current year, already have many }\end{array}$ & $5 / 10$
\end{tabular}




\begin{tabular}{|c|c|c|}
\hline \multirow[t]{2}{*}{ Revenues } & $\begin{array}{l}\text { support the organization at it early } \\
\text { stage. }\end{array}$ & $5 / 10$ \\
\hline & Lessons learn on the market analysis & \\
\hline Market Intelligence & $\begin{array}{l}\text { Good market understanding by } \\
\text { interaction with well-established }\end{array}$ & $7 / 10$ \\
\hline & $\begin{array}{l}\text { players and serving real customers } \\
\text { with real feedbacks. }\end{array}$ & \\
\hline & Strong improvement to the & \\
\hline Organization Capability & $\begin{array}{l}\text { management and R\&D team to gather } \\
\text { explicit and tacit knowledge. }\end{array}$ & $10 / 10$ \\
\hline IP & $\begin{array}{l}\text { Medium IP resulted from operating } \\
\text { this space. }\end{array}$ & $6 / 10$ \\
\hline $\begin{array}{l}\text { Project Space Creation } \\
\text { Process }\end{array}$ & $\begin{array}{l}\text { Project creation process was easy, well } \\
\text { fined-tuned. }\end{array}$ & $5 / 10$ \\
\hline $\begin{array}{l}\text { Platform Advancement } \\
\text { outputs }\end{array}$ & Platform advancement is very strong & $5 / 10$ \\
\hline Integrations & $\begin{array}{l}\text { Partner Acquisition and or number of } \\
\text { integrations into the supply chain. }\end{array}$ & $2 / 10$ \\
\hline Cost & $\begin{array}{l}\text { Cost for operating the space is } \\
\text { intermediate. }\end{array}$ & $8 / 10$ \\
\hline Market fit & $\begin{array}{l}\text { Very well market fit, simple value } \\
\text { proposition, established competitors } \\
\text { allow to better understand the market } \\
\text { fit. }\end{array}$ & $5 / 10$ \\
\hline Revenue Model & $\begin{array}{l}\text { Good revenue model, supported by } \\
\text { proven model offered by established } \\
\text { competitors. }\end{array}$ & $5 / 10$ \\
\hline
\end{tabular}

Criterion of profitability from the outcomes: $57.2 \%$

Events Space Evaluation Matrix

Table 21 Phase evaluation matrix for event project space

\begin{tabular}{llll} 
Outcomes vs Phase & Opportunity & Secure & Gain Legitimacy \\
\hline
\end{tabular}




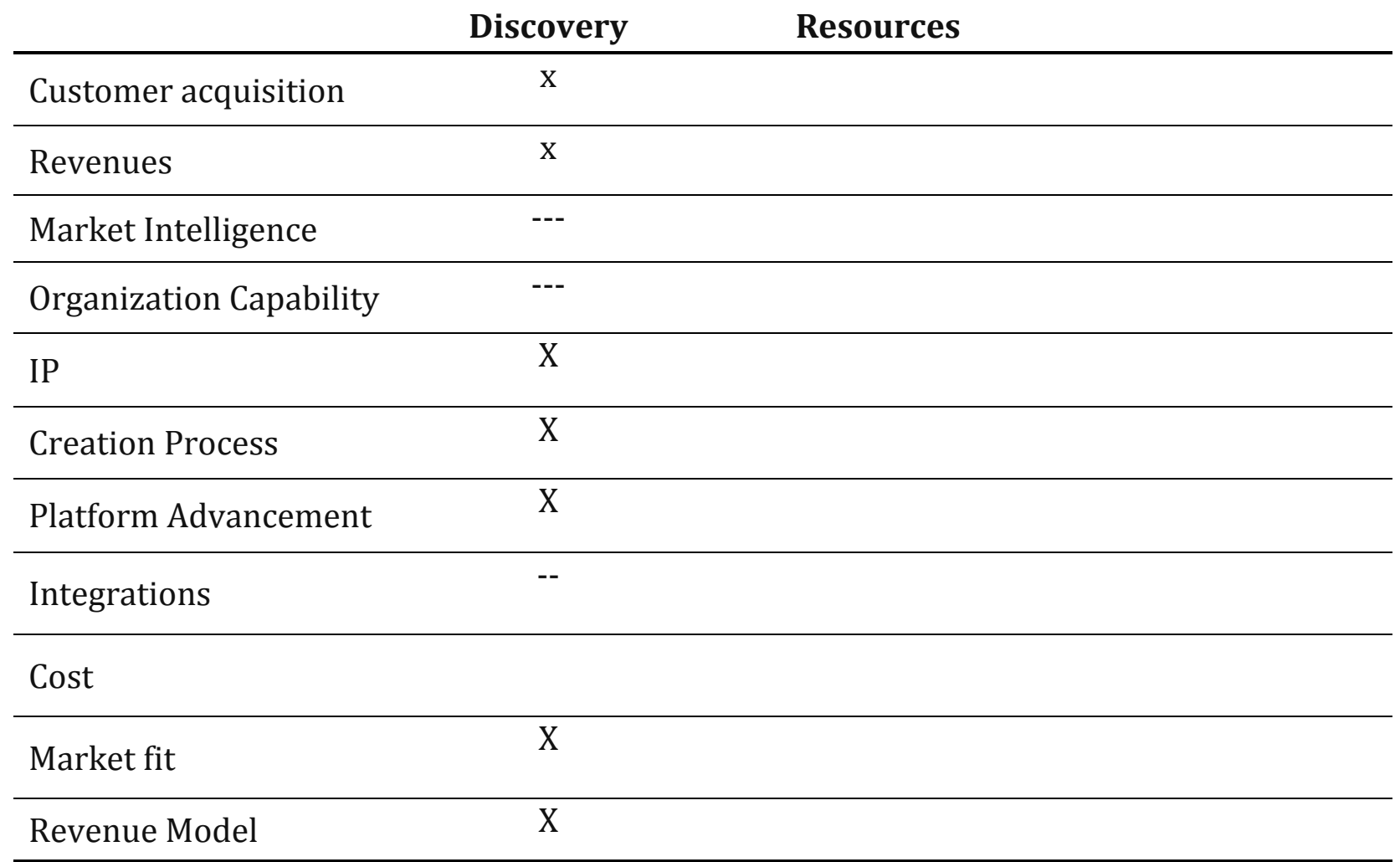

The project space progressed up to the first phase. Decision was made to keep at that phase and not to secure resources or gain legitimacy at this point. Criterion for profitability was not obvious.

\subsection{Real Estate Project Space}

The real estate market is well defined. The niched market is well defined, but the job-to-be-done is not precise yet.

\section{Attributes}

The following table illustrates the Real Estate Space Attributes Results.

Table 22 Real Estate attributes evaluation table 
Opportunity Discovery

Market Scope

Job-to-be-done is defined, very niched.

$6 / 10$

Environmental

Dynamism

Change is low

$8 / 10$

Competition Intensity

High

$9 / 10$

Product Innovation

Very high

$7 / 10$

Revenue Model

$7 / 10$

\section{Gain Legitimacy}

Marketing Intensity

With the help of well-established ecosystem, marketing intensity is low and uses the ecosystem as a marketing support platform.

Risk

Risk level is low

Platform Advancement

Degree of platform advancement is very high.

Strong synergy with the current

Synergy platform. $90 \%$ of the current platform is re-used.

\section{Resources}

Financial resources

Small

$3 / 10$

Size of team

Minimal resources on the development.

Supply chain

Well-established, but incumbents are

integration

hard to move

$1 / 10$

R\&D Investment

Small R\&D investment.

$5 / 10$

Criterion of profitability from the project space attributes: $50.7 \%$

Probes

One (1) project probe has been analyzed and interacted with.

\section{Outcomes}


The following table illustrates the outcomes from operating the Real Estate project space.

Table 23 Real Estate Project Space outcomes

\begin{tabular}{|c|c|c|}
\hline Outcomes & Description & Evaluation Results \\
\hline Customer acquisition & $\begin{array}{l}\text { Expected to attain } 500 \text { customers } \\
\text { within current year, already have many } \\
\text { direct customer intention agreement. }\end{array}$ & $1 / 10$ \\
\hline Revenues & $\begin{array}{l}\text { Project revenues are sufficient to } \\
\text { support the organization at it early } \\
\text { stage. }\end{array}$ & $5 / 10$ \\
\hline Market Intelligence & $\begin{array}{l}\text { Lessons learn on the market analysis } \\
\text { Good market understanding by } \\
\text { interaction with well-established } \\
\text { players and serving real customers } \\
\text { with real feedbacks. }\end{array}$ & $6 / 10$ \\
\hline Organization Capability & $\begin{array}{l}\text { Strong improvement to the } \\
\text { management and R\&D team to gather } \\
\text { explicit and tacit knowledge. }\end{array}$ & $6 / 10$ \\
\hline IP & $\begin{array}{l}\text { Medium IP resulted from operating } \\
\text { this space. }\end{array}$ & $5 / 10$ \\
\hline $\begin{array}{l}\text { Project Space Creation } \\
\text { Process }\end{array}$ & $\begin{array}{l}\text { Project creation process was easy, well } \\
\text { fined-tuned. }\end{array}$ & $5 / 10$ \\
\hline $\begin{array}{l}\text { Platform Advancement } \\
\text { outputs }\end{array}$ & Platform advancement is very strong & $5 / 10$ \\
\hline Integrations & $\begin{array}{l}\text { Partner Acquisition and or number of } \\
\text { integrations into the supply chain. }\end{array}$ & $2 / 10$ \\
\hline Cost & $\begin{array}{l}\text { Cost for operating the space is } \\
\text { intermediate. }\end{array}$ & $7 / 10$ \\
\hline Market fit & $\begin{array}{l}\text { Very well market fit, simple value } \\
\text { proposition, established competitors } \\
\text { allow to better understand the market } \\
\text { fit. }\end{array}$ & $5 / 10$ \\
\hline Revenue Model & $\begin{array}{l}\text { Good revenue model, supported by } \\
\text { proven model offered by established } \\
\text { competitors. }\end{array}$ & $5 / 10$ \\
\hline
\end{tabular}

Criterion of profitability from the outcomes: $47 \%$ 


\section{Real Estate Space Evaluation Matrix}

Table 24 Real Estate Phase Evaluation Matrixes

\begin{tabular}{|c|c|c|c|}
\hline Outcomes vs Phase & $\begin{array}{c}\text { Opportunity } \\
\text { Discovery }\end{array}$ & $\begin{array}{c}\text { Secure } \\
\text { Resources } \\
\end{array}$ & Gain Legitimacy \\
\hline Customer acquisition & --- & & \\
\hline Revenues & --- & & \\
\hline Market Intelligence & $\mathrm{X}$ & & \\
\hline Organization Capability & --- & & \\
\hline IP & --- & & \\
\hline Creation Process & --- & & \\
\hline Platform Advancement & --- & & \\
\hline Integrations & -- & & \\
\hline Cost & --- & & \\
\hline Market fit & $\mathrm{X}$ & & \\
\hline Revenue Model & --- & & \\
\hline
\end{tabular}

The results from operating this project space reached only the first phase. Based on market intelligence, the project space has been stopped at this point. Strong indicator provides evidence it's hard to displace the incumbent.

\subsection{Generic Platform Integration Project Space}


The generic platform integration is the most obscure. The job to be done is not well defined; it depends on each probe. The main value proposition is to beautify partners' contents.

\section{Attributes}

The following table illustrates the Generic Platform Integration Space Attributes

Results.

Table 25 Generic Platform Project Space Attributes Evaluation

\begin{tabular}{|c|c|c|}
\hline Attributes & Descriptions & Evaluation Result \\
\hline \multicolumn{3}{|l|}{ Opportunity Discovery } \\
\hline Market Scope & Job-to-be-done is defined, very niched. & $2 / 10$ \\
\hline $\begin{array}{l}\text { Environmental } \\
\text { Dynamism }\end{array}$ & Change is low & $5 / 10$ \\
\hline Competition Intensity & High & $7 / 10$ \\
\hline Product Innovation & Very high & $7 / 10$ \\
\hline Revenue Model & & $4 / 10$ \\
\hline \multicolumn{3}{|l|}{ Gain Legitimacy } \\
\hline Marketing Intensity & $\begin{array}{l}\text { With the help of well-established } \\
\text { ecosystem, marketing intensity is low } \\
\text { and uses the ecosystem as a marketing } \\
\text { support platform. }\end{array}$ & $5 / 10$ \\
\hline Risk & Risk level is low & $5 / 10$ \\
\hline Platform Advancement & $\begin{array}{l}\text { Degree of platform advancement is } \\
\text { very high. }\end{array}$ & $8 / 10$ \\
\hline Synergy & $\begin{array}{l}\text { Strong synergy with the current } \\
\text { platform. } 90 \% \text { of the current platform } \\
\text { is re-used. }\end{array}$ & $2 / 10$ \\
\hline \multicolumn{3}{|l|}{ Resources } \\
\hline Financial resources & Small & $3 / 10$ \\
\hline Size of team & $\begin{array}{l}\text { Minimal resources on the } \\
\text { development. }\end{array}$ & $2 / 10$ \\
\hline $\begin{array}{l}\text { Supply chain } \\
\text { integration }\end{array}$ & $\begin{array}{l}\text { Well-established, but incumbents are } \\
\text { hard to move }\end{array}$ & $1 / 10$ \\
\hline
\end{tabular}


Criterion of profitability: $41.5 \%$

Probes

Three (3) probes have been analyzed and interacted with.

\section{Outcomes}

The following table illustrates the outcome from operating the generic platform project space.

Table 26 Generic Platform project space outcomes evaluation

\begin{tabular}{|c|c|c|}
\hline Outcomes & Description & Evaluation Results \\
\hline Customer acquisition & & $1 / 10$ \\
\hline Revenues & & $1 / 10$ \\
\hline Market Intelligence & & $1 / 10$ \\
\hline Organization Capability & & $5 / 10$ \\
\hline IP & & $6 / 10$ \\
\hline $\begin{array}{l}\text { Project Space Creation } \\
\text { Process }\end{array}$ & & $5 / 10$ \\
\hline $\begin{array}{l}\text { Platform Advancement } \\
\text { outputs }\end{array}$ & & $5 / 10$ \\
\hline Integrations & & $2 / 10$ \\
\hline Cost & & $8 / 10$ \\
\hline Market fit & & $5 / 10$ \\
\hline Revenue Model & & $5 / 10$ \\
\hline
\end{tabular}

Criterion of profitability from the outcomes: $40 \%$.

Generic Platform Integration Space Evaluation Matrix

Table 27 Generic Platform phase evaluation

\begin{tabular}{|c|c|c|c|}
\hline Outcomes vs Phase & $\begin{array}{l}\text { Opportunity } \\
\text { Discovery }\end{array}$ & $\begin{array}{c}\text { Secure } \\
\text { Resources }\end{array}$ & Gain Legitimacy \\
\hline
\end{tabular}




\begin{tabular}{lcl} 
Customer acquisition & -- & \\
\hline Revenues & --- & \\
\hline Market Intelligence & $\mathrm{X}$ & \\
\hline Organization Capability & $\mathrm{X}$ & \\
\hline IP & --- & $\mathrm{X}$ \\
\hline Creation Process & --- & $\mathrm{X}$ \\
\hline Platform Advancement & $\mathrm{X}$ & \\
\hline Integrations & -- & \\
\hline Cost & --- & \\
\hline Market fit & $\mathrm{X}$ & \\
\hline Revenue Model & $\mathrm{X}$ & \\
\hline
\end{tabular}

Generic platform integration space experimentation progressed up to the secure resources stage. Signals from the project probes provided strong indicator the criterion for profitability is not inline with the organization objective.

\subsection{R\&D Project Space}

The $R \& D$ project space is a vague market again. In this case, the job to be done is very complex. We are experimenting with many innovative ideas, where the job is not well served by the market.

\section{Attributes}

R\&D Space Attributes Results

Table 28 R\&D project space attributes evaluation
Attributes
Descriptions
Evaluation Results

\section{Opportunity Discovery}


Market Scope

Environmental

Dynamism

Competition Intensity

Product Innovation

Revenue Model

Gain Legitimacy

Marketing Intensity

Risk

Platform Advancement

Synergy

\section{Resources}

Financial resources

Size of team

Supply chain

integration

R\&D Investment
Job-to-be-done is defined, very niched.

$6 / 10$

Change is high

$5 / 10$

High

$5 / 10$

Very high

$10 / 10$

$1 / 10$

With the help of well-established ecosystem, marketing intensity is low and use the ecosystem as a marketing support platform.

Risk level is low

$1 / 10$

Degree of platform advancement is very high.

$10 / 10$

Strong synergy with the current

platform. $90 \%$ of the current platform

$2 / 10$

is re-used.

Medium

$1 / 10$

Mediuem.

$3 / 10$

Well-established, but incumbents are hard to move

$2 / 10$

Large R\&D investment.

$1 / 10$

Criterion of profitability: $40 \%$

Probes

Two (2) probes have been analyzed and interacted with. Half of the project probes are with platform partners. The other half is with direct customers interactions.

\section{Outcomes}

The outcomes are described in the following table 29.

Table 29 R\&D Project space outcomes evaluation 


\begin{tabular}{|c|c|c|}
\hline Customer acquisition & $\begin{array}{l}\text { Expected to attain } 500 \text { customers } \\
\text { within current year, already have many } \\
\text { direct customer intention agreement. }\end{array}$ & $1 / 10$ \\
\hline Revenues & $\begin{array}{l}\text { Project revenues are sufficient to } \\
\text { support the organization at it early } \\
\text { stage. }\end{array}$ & $1 / 10$ \\
\hline Market Intelligence & $\begin{array}{l}\text { Lessons learn on the market analysis } \\
\text { Good market understanding by } \\
\text { interaction with well-established } \\
\text { players and serving real customers } \\
\text { with real feedbacks. }\end{array}$ & $2 / 10$ \\
\hline Organization Capability & $\begin{array}{l}\text { Strong improvement to the } \\
\text { management and R\&D team to gather } \\
\text { explicit and tacit knowledge. }\end{array}$ & $10 / 10$ \\
\hline IP & $\begin{array}{l}\text { Medium IP resulted from operating } \\
\text { this space. }\end{array}$ & $10 / 10$ \\
\hline $\begin{array}{l}\text { Project Space Creation } \\
\text { Process }\end{array}$ & $\begin{array}{l}\text { Project creation process was easy, well } \\
\text { fined-tuned. }\end{array}$ & $1 / 10$ \\
\hline $\begin{array}{l}\text { Platform Advancement } \\
\text { outputs }\end{array}$ & Platform advancement is very strong & $10 / 10$ \\
\hline Integrations & $\begin{array}{l}\text { Partner Acquisition and or number of } \\
\text { integrations into the supply chain. }\end{array}$ & $5 / 10$ \\
\hline Cost & $\begin{array}{l}\text { Cost for operating the space is } \\
\text { intermediate. }\end{array}$ & $2 / 10$ \\
\hline Market fit & $\begin{array}{l}\text { Very well market fit, simple value } \\
\text { proposition, established competitors } \\
\text { allow to better understand the market } \\
\text { fit. }\end{array}$ & $1 / 10$ \\
\hline Revenue Model & $\begin{array}{l}\text { Good revenue model, supported by } \\
\text { proven model offered by established } \\
\text { competitors. }\end{array}$ & $1 / 10$ \\
\hline
\end{tabular}

Criterion of profitability from the outcomes: $40 \%$.

R\&D Space Evaluation Matrix

Table 30 R\&D Phase evaluation matrix

\begin{tabular}{lccc} 
Outcomes vs. Phase & $\begin{array}{c}\text { Opportunity } \\
\text { Discovery }\end{array}$ & $\begin{array}{c}\text { Secure } \\
\text { Resources }\end{array}$ & Gain Legitimacy \\
\hline
\end{tabular}




\begin{tabular}{lll} 
Customer acquisition & --- & --- \\
\hline Revenues & --- & --- \\
\hline Market Intelligence & $\mathrm{X}$ & $\mathrm{X}$ \\
\hline Organization Capability & --- & $\mathrm{X}$ \\
\hline IP & --- & --- \\
\hline Creation Process & --- & $\mathrm{X}$ \\
\hline Platform Advancement & --- & --- \\
\hline Integrations & -- & $\mathrm{X}$ \\
\hline Cost & --- & --- \\
\hline Market fit & $\mathrm{X}$ & --- \\
\hline Revenue Model & --- & \\
\hline
\end{tabular}

The following table describes the results from operating the innovation engine, for each component of the system.

Table 31 summarizes the system-level results from each component of the innovation engine

Component Data Definition Results

\section{Project Space}

Number and type of project space created

5

and operated

Project Space Attributes collected

5 tables, one for each space

Project Space Outcomes

17

Project Evaluation

1 


\section{Organization}

\section{Business}

Ecosystem

Shareholders 5

Board of advisors 5

Organization 1

Staffs employed and generated 3 local, 5 offshore

$\begin{array}{ll}\text { End users } & \text { NULL - not collected yet } \\ \text { Customers } & 15 \\ \text { Partners } & 5 \\ \text { Supply chain } & 2\end{array}$

\section{Platform}

IP created while operating the innovation $\quad 5$ engine and its project space

Infrastructure outputs

5 servers

Software elements created

3 - server, client, native mobile app software

Common Assets created within the $\mathrm{X}$ Zines created, other assets not innovation engine measured yet.

\subsection{Lessons Learns Collected}

This section captures the lessons learn based on the experience of operating the innovation engine using the Project Space Framework for the Zination Platform.

\subsubsection{Lessons Learned from operating the Zination Platform}

The platform is designed to be generic; hence, applying it to other markets was possible. Because of that nature, it also creates major challenges in identifying the right market fit.

- Creating a generic platform is a versatile method to move from one market to another, however finding the right market fit becomes a big challenge.

- Being very focus in bringing the minimum viable product to the market place is easier said than done 
- Identifying the minimum viable job can help better find the right market fit

- Moving into a new market domain without previous experience from the founding team generates challenge to understand that market

- Online marketing is a large and vague market that the founding team did not sized properly at it early stage

- Operating a new venture without solid method to secure resources is highly risky

- Being focused day one would have helped to bring the Zination platform earlier into the market place

- Common shared assets is a very power driver of the platform advancement

- Metrics are critical to help monitor the platform advancement

- Solving one well-defined problem is better than trying to solve a very large problem

- Diverse team members with different opinions are important to the organization health

\subsubsection{Lessons Learned from the Project Space}

We originally experiment rapidly the e-commerce market niche without a proper methodology and without a supporting probing instrument. The project space was maintained for a long period of time (figure 6) until it becomes relevant again when a partnership was established with a platform player within that domain. After the partnership was established, we were able to better understand that market and get insight into a market that was new to us. This partnership allows our team to better understand the business context MacCormack et al. (2007).

Follow is a list of lessons learn:

- Project Space experimentation must be efficient (minimizing investment in time and resource) and fail fast 
- Failed project space can be revived

- Defining a project space based on the job-to-be-done ease the analysis of market fit

- Project Space where the partners are weak can drains new venture resources and time

- Partnering with other small new ventures tends to fail for many reasons

- A well established market is easier to

- Finding the correct partnership is a critical point in project space testing and validation

- To increase the odd for the platform advancement, design the innovation engine around the architecture of collaboration

- The concept of opportunity and project are not the same, they overlaps, but a project is a seized opportunity

- Open the platform to project space's partners helps validate the market niche

- Create high-value shareable assets increase the platform advancement

- Early analysis and weighting of project space attributes can help gauze market fit

\subsubsection{Lessons Learned from Project Probes}

The following describes the lessons learn from managing project probes:

- Try to probe for both business partners and customers;

- Probe with a small established player in the market domain to gather better understand of the target market;

- Each project probe must have a well intend outcomes, some probes are for market understanding, other are for revenue generation, others are for research and development purpose;

- Create a project probe that serve a real paying customer provide strong indicator for the survival of a project space;

- A project probe is an instrument used by the project space framework to test the market place and enables verification of assumptions and theory; a 
project probe contrary to a market analysis is a real life inspection into the market place;

\subsubsection{Lessons Learned from the Research Methodology}

The following are the lessons learn from the research methodology:

- The innovation engine is a powerful framework to crystallize the visual understanding of the entire global start organizational structure and interactions;

- The using the project space framework and the project probe concept enforce the understanding that at it early stage, new venture must find rapidly most relevant market fit;

- The research methodology bring disciplines into the operation of a new venture;

- Continually create new project probes is critical for the survival of a new venture. 


\section{Chapter 6 - Discussion}

This chapter summarizes this research key finding. Discussion on the results of the research is covered; connecting the research to literature in relevant domains is described, finally propositions are provided to help new venture to operate the innovation engine using the project space framework.

\subsection{Discussion of results}

The primary intent of this research is to determine how the innovation engine can be adapted and used by tech entrepreneurs to help new ventures to better size opportunities and better cope with opportunity discovery process in the most profitable method.

Adaption of the innovation engine concept from Bailetti (2013):

1) Applied the context to a technology new venture, in a real research project;

2) Modified the "Project Community" component of the initial model into the "Project Space" component; and

3) Extended the original "Project Community" component to include a new Project Space Framework to help new venture cope with the initial opportunity search phase of the entrepreneurial process.

The following results summarized the process used by the research methodology. We will discuss the results, after explaining in more details the collected data.

\subsubsection{Project Spaces Lifespan}

The following diagram illustrates the project lifespan during the research period. 


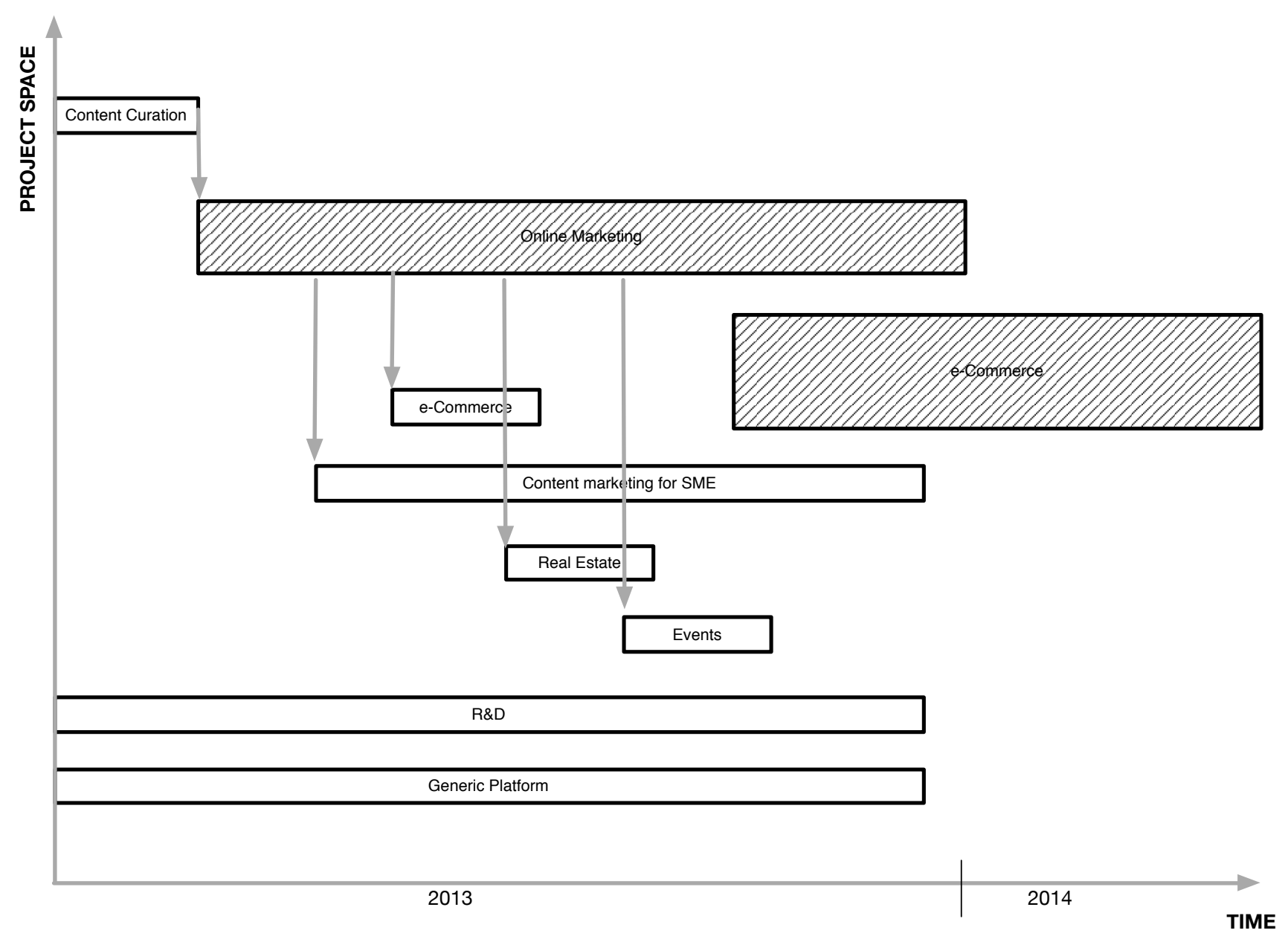

Figure 6 - Project Space progression during the research period

At the start of the research, the innovation engine, the project space framework and the project probe are non-existent. During that early stage, we were talking about market segmentation, global start, and opportunity and customer validations in general term. We used the same instruments like our peer including business plan, business canvas model, marketing plan.

The research started from the focus on viral product design, community building and shifted toward the innovation engine model, after Bailetti (2013) published the framework. Working on the research to adapt the innovation engine for a webbased new venture, it motivated the need to create the project space concept. Our management team was knowledgeable of the multi-sided market concept, the 
business ecosystem and the keystone advantage concept. However, with the crystallized innovation engine model, it enables our team to visualize the connections between the major components and to illustrate interactions between components, the importance of the business ecosystem, the platform and method to enable the platform advancement.

The framework has been created later after the research progress further, however the steps following during the use case were already present.

After operating the Content Curation Project Space, lessons learn from operating that space allows us to improve the knowledge box (I1) and to create better screening, early valuation matrix for the outcomes and to come to the conclusion the space must be STOPPED. With gathered knowledge on that first space, it's provides us with hint to look at the online marketing space. Many project probes have been created to verify the validity of the space. Many customers have been reached to allows further validation for a proposed job-to-be done.

Table 32 summarizes the project space progression during the research period

\begin{tabular}{|c|c|c|c|}
\hline Time & Project Space & Impact & Outcomes \& Lessons Learn \\
\hline T0-A & Content Curation & Online Marketing & $\begin{array}{l}\text { - } \text { Move out of space } \\
\text { - IP creation } \\
\text { - } \text { Original Platform creation }\end{array}$ \\
\hline T1 & Online Marketing & $\begin{array}{l}\text { Content Marketing } \\
\text { for SME }\end{array}$ & $\begin{array}{l}\text { - Revenue / IP Creation } \\
\text { - } \text { Platform advancement } \\
\text { - } \text { Ecosystem building } \\
\text { - } \text { Proin legitimacy } \\
\text { Process to create other probes and other } \\
\end{array}$ \\
\hline $\mathrm{T} 2$ & Online Marketing & E-Commerce & $\begin{array}{l}\text { - First investigation into a new space } \\
\text { - Insufficient probes created, project } \\
\text { space stay dormant }\end{array}$ \\
\hline
\end{tabular}


- Market knowledge

T3 Online Marketing Real Estate

- Incumbent hard to displace

- Space is put in dormant

T4 Online Marketing Events

- Use space for marketing

- New IP generated

- Lessons on revenue model

- Partnership

- Supply chain integration

- More probes generated for different

R\&D \& Online

T5

Marketing \&

Generic Platform

Integration
E-Commerce categories: customers probes, partner probes, ecosystem probes

- Decision making matrix

- New IP generated
- New IP

- Platform advancement
T0-B

$\mathrm{R} \& \mathrm{D}$

Generic Integration

T0-C
- New IP

- Lesson learn about partnership, improve the decision making matrix

- New revenue model

- Interfaces produced

\subsubsection{Summary of the results from operating the project spaces}

The following table summarizes the criterion results from evaluating the project space during both the screen phase and the valuation phase.

Table 33 Final Profitability evaluation

\begin{tabular}{lcc} 
Project Spaces & $\begin{array}{c}\text { Attributes } \\
\text { Criterion }\end{array}$ & $\begin{array}{c}\text { Outcomes } \\
\text { Criterion }\end{array}$ \\
\hline E-Commerce & $92 \%$ & $90 \%$ \\
\hline
\end{tabular}




\begin{tabular}{lll}
\hline Online Marketing & $63 \%$ & $58 \%$ \\
\hline Event Spaces & $54 \%$ & $58 \%$ \\
\hline Real Estate & $51 \%$ & $47 \%$ \\
\hline Generic Integration & $42 \%$ & $40 \%$ \\
\hline R\&D & $40 \%$ & $40 \%$ \\
\hline
\end{tabular}

\subsubsection{Final Decision Results}

The following table illustrates the decision outcomes from operating the project spaces during the research period.

Table 34 summarizes final decision for each project space

\begin{tabular}{lcl}
\hline \multicolumn{1}{c}{ Project Spaces } & Decisions & \multicolumn{1}{c}{ Arguments } \\
\hline E-Commerce & GO & Strong signal to continue and grow the project space. \\
\hline Online Marketing & STANDBY & $\begin{array}{l}\text { Not enough signal to keep investing, the space is but in } \\
\text { standby. More project probes are required. }\end{array}$ \\
\hline Event Spaces & STANDBY & A strong signal to stop probing this space for now. \\
\hline Real Estate & STOP & $\begin{array}{l}\text { Strong signal to stop probing, the incumbents are hard to } \\
\text { displace. }\end{array}$ \\
\hline Generic Integration & STOP & Medium signal to stop investing in this space for now. \\
\hline R\&D & STOP & $\begin{array}{l}\text { Medium signal to keep this space going on to ensure new } \\
\text { innovation can contribute to the advancement of the }\end{array}$ \\
\hline
\end{tabular}


platform.

Based on the profitability criterion, Table summarizes our final decision on which project space to keep investing and which to put on standby, or to close completely.

The anomaly in the decision-making happens once with respect to the R\&D space. Based on the criterions of profitability, the R\&D project should not be pursued. However, it's a discretionary decision from the founding team to maintain that project space alive.

\section{Discuss e-Commerce results}

Based on our evaluation, the e-Commerce Project space attributes criterion evaluation resulted in a very high evaluation (92\%). From these evaluation criterion results, it's a strong signal the e-commerce project space can be a good fit for the new venture. Hence, it provides a strong indicator to progress the project space further into the project space framework phases.

The Outcomes Criterions evaluation results for the e-commerce project space are also resulting in a strong outcomes criterion value (90\%).

From the outside, we can conclude from these two evaluations criterion, this project space is the right one for the new venture to invest into. However, as illustrates by figure 6, it was not the case. Full investment into the e-Commerce Project Space was actually committed only at a later stage of the new venture life.

The project space is a GO. 
Lessons learn from operating this project space was that early in the life of the new venture, we didn't have proper evaluation criterion. The project space was maintained and more project probes were created. With more experiences from operating other project spaces, the attributes evaluation criterion were performed multiple times, with more accuracy as it's based inputs from Knowledge Box. The results from the new evaluation provides better indicator for the management team to progress further and to fully invest into that space. The major lessons learn from this experiment is to never stop probing a space. Management team can stop investing into a stopped project space, but should always keep informed of the evolution of a space and continue to collect knowledge as the criterion of profitability can change overtime. An evaluation by an informed team can increase the accuracy of the criterion; hence it's recommended to bring other team members to help in this task.

The evaluation tool can be used only as an indicator and its results are based on our own experience, market condition and organizational capability at that point. The value of the tool is in providing a consistent evaluation method for all project space, within the same condition.

\section{Discuss Online Marketing Results}

The new venture was created originally to tackle problems related to online marketing market. This project space has progressed in all phases of the project space framework. Evaluation of the project space has been performed at the beginning of the new venture, in the middle and toward the end of the research period. The last evaluation results are from a consistent evaluation criterion, which results in the attributes criterion of $63 \%$. 
The outcomes evaluation of the project space is $58 \%$.

The project space is put in STANDBY.

Lessons learn from operating this project space provide evidence for our stakeholders that a first entry into one project space is not necessarily the right

choice. The new venture had to pivot away from this space temporarily and move into another more appropriate project space, based on many business conditions.

\section{Discuss Events Project Space results}

The Event Project Space comes into existence in the middle of the research period. The project space was created to serve business in enabling them to real time capture events during occasions like tradeshow, product launch, and produce real time beautiful online magazine for sharing and branding purpose.

Attributes criterion for this space gives a value of 54\%. This number provides us with an indicator that is in the low scale for our decision making to STOP or put on STANDBY. Based on results from operating the project space, the value is $58 \%$. This is the tiebreaker that helps our management team to put the project space on STANDBY.

\section{Discuss Real Estate Project Space results}

The real estate project space was created to help realtors to better promote houses for sale by producing beautiful online magazines, on the fly. The value proposition is sufficiently attractive for us to analyze the space and create some early project probes. 
The attributes criterion of $51 \%$ and the results of $47 \%$ provide sufficient indicator for us to STOP the opportunity discovery process. This project has not progress further.

Lessons learn from operating this project was multiples. Firstly, many business partners and advisors recommended the management team to investigate further into this space. The value proposition seems at first instance adequate to serve it customers. As more project probes are created and progress in its investigation, we found out the offering what trying to displace well-established incumbents. We come to realize, at the current stage of the new venture, we are hitting a brick wall. The project space is put in STOP mode.

\section{Discuss Generic Platform Project Space results}

The generic platform integration project space was created to serve other new venture in helping them to beautify their outputs. This is a very interesting and powerful offering to enable an ecosystem play, leverage success from partners and can contribute to viral adoption of the Zination platform.

Many project probes have been created, each one unsuccessfully. The project space has reached the secure resources phase. The attributes criterion is $42 \%$ and the outcomes criterion is $40 \%$.

The project space is put in STOP mode.

Lessons learn from operating this project space is many. Early during the new venture life, this project space was thought to be a big opportunity for improving the platform adoption. Strong partnership was created with well-intentioned business partners within the same business ecosystem. Each one team were friendly, strong network links created, motivated to succeed and committed to their respective venture. The results from the partnerships however were unsuccessful in all cases. 
We blamed these failures not to the relationship, but rather to the stage at which these ventures reached. In each case, the ventures are closer to the opportunity discovery phase or secure resource stage. Some reach the very early entrepreneurial processes of gaining legitimacy. In all cases, these ventures cannot achieve the committed integration goal and deliver because of deficient resources. Lessons learn for our organization is to focus on integrating with well-established partners to reduce business risks.

\section{Discuss Research and Development Project Space results}

The Research and Development Project Space is dedicated to bring new ideas for the new venture. The new venture started with this project space in its early life. However, as the new venture reached the point of trying to bring its innovation into the market place, investment into this space is less and less affordable.

The attributes criterion is $40 \%$ and the outcomes criterion is $40 \%$. The project space is put in STOP mode at the current time.

It might seem an anomaly to stop investing in this project space. The reality is that the new venture started in this mode for quite some time, before this research started. As the result from the R\&D shows strong evidence of its applicability in the market place, further investment in different R\&D project spaces would reduce and disperse the new venture already limited resources. To better perform and bring focus to the new venture, other R\&D projects not related to the core platform are discarded. It does not imply however that no research and development are performed in each project space discussed in this research. 


\subsubsection{Project Space Attributes \& Outcomes Evaluation}

From the results obtained throughout this research, we observed some correlation between the framework input (project space attributes evaluation) and the framework output (project space outcomes evaluation). The number of results from this research is not sufficient to automatically create a direct linking between parameters. However, this can be a good indicator to signal if a project space worth further analysis or can be discarded from the beginning.

\subsection{Theoretical Connection and Research Contribution}

This section draws connection between this research and related theoretical domain, including the contributions that this research makes to the domain knowledge.

\subsubsection{Global Start}

By adapting the innovation engine Bailetti (2013) and replacing the "project community" component with the project space framework, the methodology development within this research is not only helping new venture in pursuing a global reach objective, it contributes back to the theoretical domain. This research, by operating a real life platform, demonstrates the potential of the theoretical concept brought to life by Bailetti (2013) for new ventures in bringing their innovation into the market place.

\subsubsection{Business Ecosystem}

Iansiti and Levian (2004) describe the concept of business ecosystem in great length. The authors introduce the role that an organization can take in business ecosystem. In the case of a Global Start, the keystone role discussed by the authors is an important strategy. In this role, a keystone organization serves as the enabler 
and which have a great impact on the whole system. The design principles from Iansiti and Levian (2004) served as important guidance for the determination of the project space attributes and outcomes for this research. This research contributes back to theory by creating a framework that strongly supports the experimentation aspect of the rules. This research is a constructive research, and one of the contributions to theory is to put in practice these theoretical concepts and to create a keystone organization that has global reach capability.

\subsubsection{Constructive Research}

This research follows the constructive research methodology. In doing so, the research is developing a real-world solution, contributing back to theory by providing a real-world case study that supports a theoretical framework (e.g. the innovation engine model).

\subsubsection{Entrepreneurial Processes}

Elfring \& Hulsink (2003) discussed the three entrepreneurial processes in new venture development, these are: discovery of opportunities, securing resources, and obtaining legitimacy. These processes, argue the authors, are of importance for survival and performance for any new ventures.

This research is a direct application of the entrepreneurial processes described by the authors. The project space framework produced by this research is an application of the entrepreneurial processes in the context of innovation engine model; by bringing the three phases inside a framework for coping with early stage new venture development.

This research contributes back to this theory by providing further supporting proof within a real-world application. 


\subsubsection{Projects Concept}

Casson \& Wadeson (2007) argue "the concept of opportunity is closely related to the concept of a project, as an opportunity is essentially a project that would prove beneficial if it were exploited". In this research, we follow the concept of opportunities in that same direction. Opportunities stay as such if it's not seized and has not passed the project space framework screening process. An opportunity that passed that phase becomes a part of an organization project space portfolio. This research contributes to theory by introducing both the project space concept and the project probe concept, and confirms prior research.

\subsubsection{Project Space framework evolution during the research}

\section{Phase 1 - We started with the entrepreneurial processes}

When the research started, before the thesis is shaped into what it is, we used the common entrepreneurial processes for the new venture. We adopted the business model canvas from Alexander Osterwalder to summary the new venture plan, create the business plan standard document and capture our plan using the business plan template. 

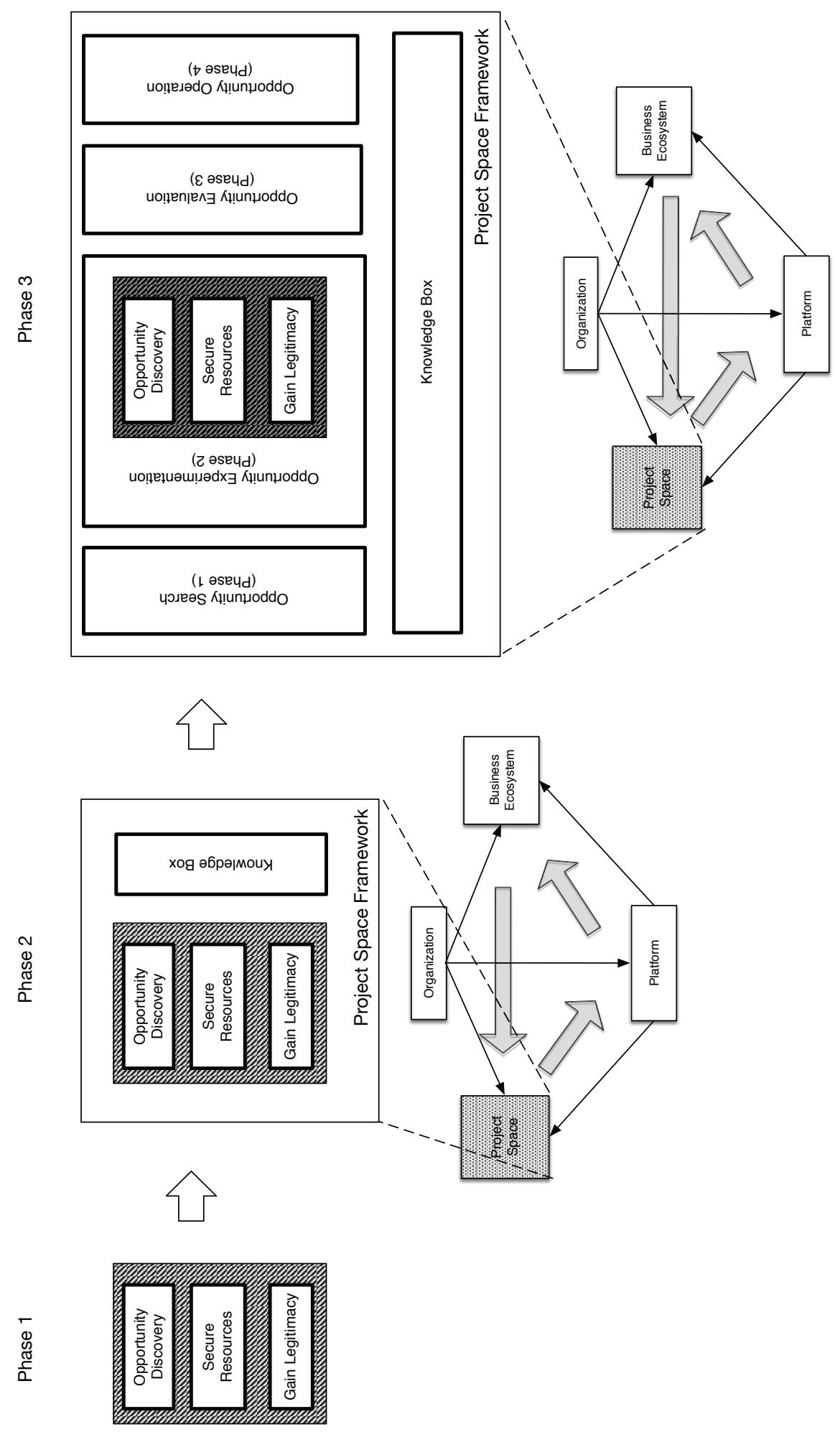

Figure 7 - Project Space Framework Evolution 
We selected one market target (Content Curation) that we somehow know and invest all our resources into that selected market niched thinking we have done our due diligence and invest in the right venture. As we progress in the opportunity discovery phase and secure resources phase, we realized that it's hard to gain legitimacy within that market. Revenue model was hard to figure out, the competitive landscape was very intense. Lessons learned from that phase motivated our founding team to look for alternatives and to pivot the new venture and use the innovation engine model to improve the odd.

\section{Phase 2 - Lessons Learn from theory to use the innovatio engine model}

The innovation engine model helped the new venture to design its business incorporating the platform component, the business ecosystem, the organization and the project space. Adoption of the innovation engine greatly improves the business strategy, added more depths into the business strategy and tactics from our new venture can adopt and get improved guidance.

\section{Phase 3 - Final Phase}

By operating the innovation engine over a period of time (less than 6 months), the knowledge box increased and lessons learned from operating multiple project spaces, creating multiple project probes enables the Project Space framework to evolve and reach the stage where it's currently. The knowledge box improved the project space attributes definition and identification. Additionally, it helps defined better project space outcomes for the measurement that are most relevant for new venture. 


\subsubsection{Links between Project Space Framework and Innovation Engine}

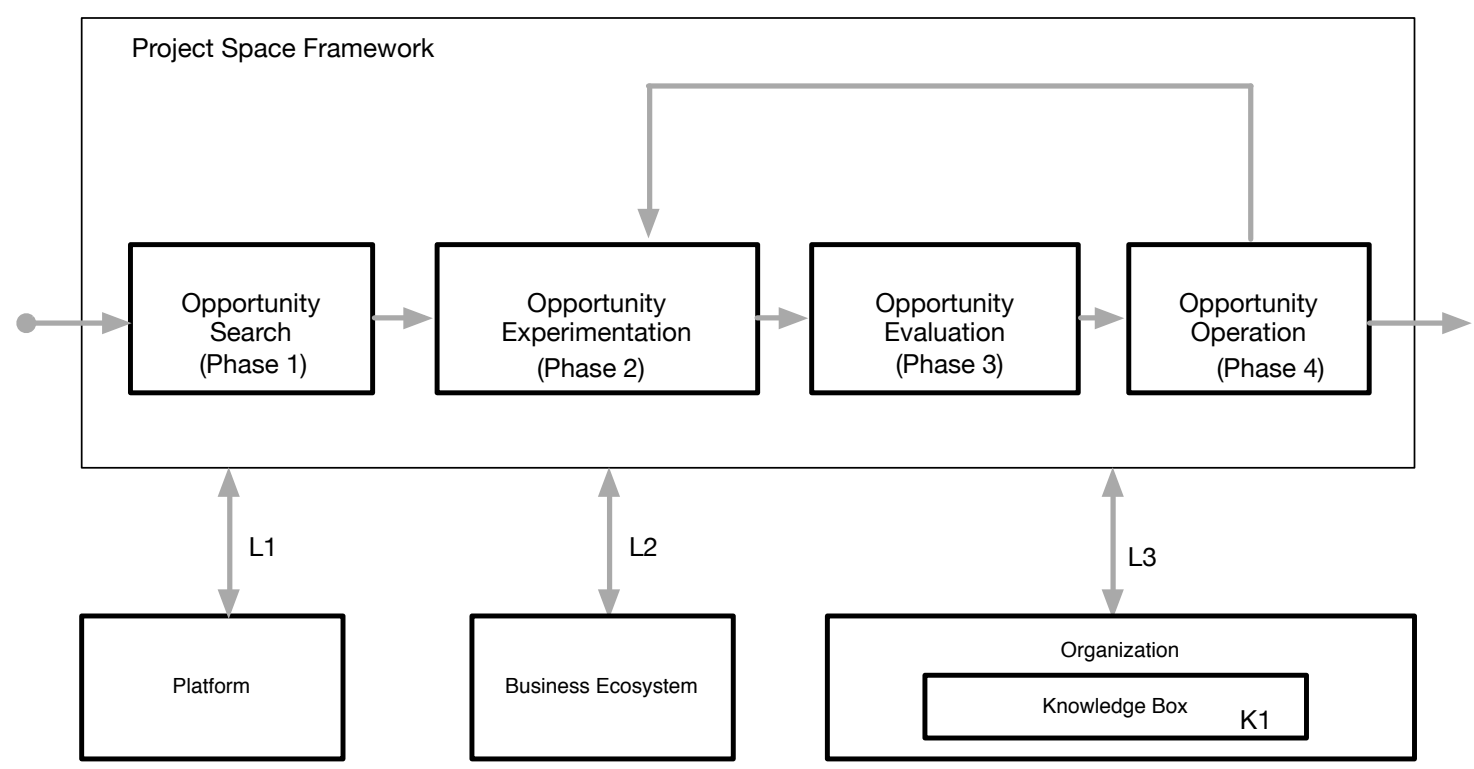

Figure 8 - Links between the project space framework and Innovation engine components

Project Space Framework is a subsystem of the entire innovation engine system architecture. This research is focused specifically on this component, describing in great length the process involved. The links from this component to the rest of the innovation engine is by mean of the links L1, L2 and L3.

L1 depicts the link with respect to Innovation Engine Platform component. It provides the method for platform access to project space and contributions of the project space back to the platform by mean of platform advancement outcomes.

L2 illustrates the link between the Project Space framework and the business ecosystem. The connection between the two components is provided by mean of access to customers, partners, channel partners and other resources. The other 
connection is by mean of the project probes that are create to tackle each job-to-bedone segment within the business ecosystem.

L3 depicts the link between the project space and the organization. This link provides the connection between the two component for access to financial resources and back and forth exchanges of lessons learns that contribute to improve a project space operation while helping the organization to better create or manage other project spaces.

\section{Discussion on Evaluation of New Project}

In the project-centered approach, it highlights the importance of the process by which projects are evaluated and selected. Processing every possible project opportunities would be an enormous task, unmanageable and non productive. It's therefore vital the screening process must be efficient and cost effective. Within this research, evaluation of new project is based on observation of the symptoms, the job-to-be-done that can be performed by the platform to serve the new opportunity, and a profitability indicator. The project space attributes and outcomes evaluation matrix are used to help guide our screening process in the most cost effective matter. When evaluation new project, we always try to detect the level of synergy with existing project space. The level of potential profitability is afterward evaluated. While using this methodology for the operation of the Zination Platform, it turns out to be effective.

\section{Discussion on Choosing the Field of Search}

For search process, Casson \& Wadeson (2007) discuss the following search approaches: 1) an inward-looking approach, 2) examining the economic environment, 3) examining the performance of currents projects.

In the first approach, the entrepreneur and the founding team is the focus point of preferences and capabilities for the search. During this research, this approach is 
extensively used, with the help of the networks around the founding team to expand the search view.

The second approach is by examining the current economic situation. Examining the environment and the economic situation provides a context of the problem and solution offered, but it has not been used in great length within this research.

The third approach helps our new venture at later stage to better filter and help improves the search, it can't be used at the beginning of the new venture.

\section{PROJECT SPACE LIFESPAN}

Project Spaces that are stopped are not necessary completely eliminated from future opportunity discovery processes. It's important to remind that sometime, project probes can be created to test the market, at regular intervals, to reevaluation the new business conditions. The best example comes during this research with respect to the e-commerce project space. The project space was not the main focus for a long period, until the right probe triggered many other probes and bring in focus the project space importance for the new venture. This opportunity would have been missed if we didn't inject more probes into the market place.

\section{Relevancy of the Innovation Engine Model}

This research was conducted using a constructive approach and where the creation of the new venture was grounded on theory. The founding team had previous startup experiences, each one had created successful new venture. 
The founding team had previous start-up experiences; each member has participated in creating a successful new venture. However, within this research, a methodology grounded on theory and experiences were used for the creation of the new venture. The results of the experience are captured in this research and we are hoping it will contribute to new venture process improvement, and mostly guide entrepreneurs by mean of a framework that can increase the odds in tackling the market place.

By mean of the innovation engine created by Bailetti et al. (2013), the model was an important guide for our founding team to visual the core components of the new venture. The value of the innovation engine was in a model that captures the most important stream of knowledge for tech new venture with a global ambition. The four major components (organizational design, business ecosystem, platform and

project space) assembled and linked together created a very powerful model to bring forth the most important elements of innovation. The model enables our team to view the new venture in a more dynamic perspective, as opposed to other model like the Business Canvas framework from Alexander Ostenwalder. Our research demonstrates the innovation engine model can be used for new venture, and we strongly recommend the model for other tech new ventures.

\subsection{Relevancy of the Project Space framework for new ventures}

This research is specifically around a new venture which business goals are to achieve global capability, produce business results that very aggressive and bold. The platform created by the new venture is intended to be a multi-sided market, creating and managing its own business ecosystem. The new venture is designed into being a keystone organization, following design guides put forth by Iansiti et al. (2004). The innovation engine has been adapted from Bailetti (2012) and the 
project space framework has been created with these objectives in mind: produce system results for the organization, results from the platform, the project space, and the business ecosystem.

Consequently, this research and its deliverables (the innovation engine and the project space framework) are relevant to new ventures, with the intent to better cope with market experimentation.

The framework enables new venture to use the evaluation criterions to evaluate opportunities in a more consistent method, providing guidance in how to progress each opportunity inside a project space concept and the importance of creating project probes to test for market fit. The project space framework it put in the context of the innovation engine model, which is a very powerful model synthesizing the keystone concept, the architecture of collaboration model, business ecosystem and lessons learn from platform concept and co-value creation stream.

The result from this research is less relevant for business with a well-defined opportunity, no need for a too complex market validation and is not creating a complex multi-sided platform. A pure product play venture or well-established organization might see less value in the framework created.

\subsection{Propositions for new venture}

Proposition 1A - Project Space that is narrow scope is more likely to progress further and innovation engine operation phase and be adopted by the organization as a profitable venture

Narrow scope project space is more likely to increase its chance of success as opposed to large scope project space 
Proposition 1B - Project space with a clear market fit can progress further within the entrepreneurial processes

Proposition 2 - Creating early linking with well-established partners improves the chance for the opportunity to evolve further within the project space development phase.

Project space can gain early legitimacy by creating linking with well-established partnerships, progressing from smaller to larger partners.

Proposition 3 - Project spaces with strong synergy contribute to improve organization capability, code sharing and contents creation within the platform and help the advancement of the platform.

Project spaces must be create in such away that synergy exist between them to leverage organization capability, code sharing and content networks.

Proposition 4 - Project space that does not need to displace incumbent has more chance of success.

Project space must handle opportunity, which the organization does not need to displace the incumbent.

Proposition 5 - Project space with strong platform advancement indicator has more chance to progress further within the entrepreneurial processes.

Proposition \#2 also can be improved by saying it's the same as the Pattern \#3 which relies on a solid and established network. Using a weak existing network is not helpful. 


\section{Chapter 7 - Conclusion \& Future Research}

This chapter draws conclusion from the research and brings forth the limitations and provides guidance for future research.

\subsection{Conclusion}

The research questions sets in the very beginning are revived in the following coupled with a short summary of how this research has addressed them.

Research question 1: Is the innovation engine model suitable for a web-based new venture?

The innovation engine model described the literature was suitable for non-for-profit organization and has been designed for the VenusCyber ecosystem. It's a fair question to know if it's applicable for a web-based new venture. By mean of this research, the innovation engine has been adapted and operated for the Zination Platform, which is governed by a real web-based organization (LassooTheWeb). The success of the organization is one good supporting proof for the validity of the model.

Research question 2: How can the project community concept adapted for a forprofit-organization?

The concept of project community was created and described by Muegge for a nonfor-profit organization and is used as part of the innovation engine. The project space concept was created replace the "project community" concept in the case of for-profit organization. This concept allows new ventures to better tackle the market fit investigation and bring the mindset into the importance of lean startup and experimentation when dealing with "heavy" innovation. Project space concept has some similitude with the project community with respect to provide 
advancement for the platform. The project space concept extends that further to include revenue outcome, risk mitigation, market fit testing. The project space concept is created to cope with the analysis of market scope by looking from the jobto-be-done view and a container of portfolio of project within the same job, having strong synergy between them.

Additionally, the project probe concept is created to provide mechanism to cope with subset concrete opportunity, within one market niche and to use it to probe the market place with minimum investment.

Research question 3: what processes new venture can used to better cope with opportunity discovery?

The project space framework allows new venture to cope with rapid innovation and market validation by mean of market experimentation with project space concept and project probes injected to test for market fit.

Alternatives for our new venture can be in the extreme scenario where a search of opportunity is performed, screened seized without supported evidence from market validation, or it can be pure stage-gate process based.

With the Project Space Framework, the process has been used on a real new venture for the creation of a web online content beautification engine called Zination. It demonstrates the potential of application for other new venture within the same domain (web-based ventures) where lean and agile development critical for the survival of the new venture. 


\subsection{Limitations}

The thesis employs the design approach to provide a solution for the problem encountered by web-based new venture to properly experiment with market fit and improve it efficiency for opportunity discovery, minimize resources waste and reduce the gain legitimacy friction. It provides specifically a project space framework guide new venture in a process that can be adopted for market testing, in the context of operating a new venture following the innovation engine model.

The model is limited to web-base new venture in its early very early phase. The current experimentation is over a 12 months period, performed by only one new venture use case. Further validations are required; applying the framework within other new ventures would provide strong evidence on the applicability of the framework for new venture.

The design centers around one new venture experiment. Increasing the number of project spaces, mostly the number of project probes would greatly support the validity of the process.

A lot of the efficiency of the process depends on the capability of the founding team and its capability to secure resources, having access to the network of business ecosystem, on top of finding the correct market fit. Hence, this process does not provide any guarantee of success to new venture in any way; it will always depend on the people around the new venture.

- The framework is around the project space

- Applicable to the opportunity phase, data gathered only for those periods

- Longer research period required to confirm the decisions has value

- Number of project probes is limited 
- Assumption was made that the organization manage to secure enough resources to experiment multiple project space without risking the life of the organization

- Depends on the successfully implementation of the organization and the platform

- Difficult to evaluate the ultimate success of the framework

Another major limitation of this research resides in the model being applied to only one real world project, where we are trying to use a not-well established method to solve a challenging problem for new tech venture while using a new model. The project community concept was defined around a well-established problem; the project space concept is around identifying the most profitable market niche for a new venture to jump into, therefore there is more uncertainty. Solving this uncertainty in the most profitable method is a challenging task.

\subsection{Future Research}

This research has many limitations, because of the limitation of the research period, its does not capture sufficient evidences generalize the validity of the framework for other new venture.

The framework requires further research and applicability within new venture in other domains, within more matured ventures.

The project space attributes are grounded on theory, however it can be tailored and specialized specifically for other type of ventures. The project probe concept can be further clarified and detailed to improve the efficiently in operating one project space. 
Future research can help to compare between venture that are centered on the organization, the project space, the platform or the ecosystem. Depending on the new venture investment size one component, a future research can helps venture to better invest resources on the most efficient component, and for which reason.

Future research can also follow the path to create a new activity based business model framework based on the Innovation Engine Architecture and the Project Space framework such that can reflect the dynamic nature a tech new ventures.

An improved screening process can be designed to help better find the right fit, minimizing investment cost, reducing risks and increasing the search for potentially profitable opportunities.

Future research can also investigate into providing a method to grow a project space that includes a subset of the business ecosystem. 


\section{Chapter 8 - References}

Bailetti, T. (2013). Developing an Innovation Engine to Make Canada a Global Leader in Cybersecurity. TIM Review, (August 2013).

Bailleti, T. (2012). The "born global" disruption. Retrieved from FrancisMoran and Associates special report. http://francis-moran.com/index.php/marketingstrategy/the-born-global- disruption/

Bailetti, T. (2012b). Technology Entrepreneurship: Overview, Definition, and Distinctive Aspects. TIM Review, (February 2012).

Bailetti, T. (2010a). Keystone Off-The-Shelf. Open Source Business Resource, (September 2010).

Weiss, M. (2010). Keystone: Adjective or Noun? TIM Review, (September 2010)

Bailetti, T . (2010b). Blueprint and approach to grow revenue in small technology companies. Open Source Business Resource, (June 2010).

Muegge, S . (2011). Business Ecosystems as Institutions of Participation: A Systems Perspective on Community-Developed Platforms. Technology Innovation

Management Review, (November 2011).

Boudreau, K. J., \& Hagiu, A. 2009. Platform Rules: Multi-Sided Platforms as

Regulators. Platforms, Markets and Innovation:163-191. Northampton, MA: Edward Elgar Publishing, Inc.

Brown, P. O., Eisen, M. B., \& Varmus, H. E. 2003. Why PLoS Became a Publisher. PLoSBiol, 1(1). 
Iansiti, M., \& Levien, R. 2002. The new operational dynamics of business ecosystems: Implications for policy, operations and technology strategy. Harvard Business School Working Paper, (03-030).

lansiti, M., \& Levien, R. 2004a. The Keystone Advantage: What the New Dynamics of Business Ecosystems Mean for Strategy, Innovation, and Sustainability. Harvard Business Press.

lansiti, M., \& Levien, R. 2004b. Strategy as ecology. Harvard Business Review, 82(3): 68-78.

lansiti, M., \& Levien, R. 2004c. Keystones and dominators: Framing operating and technology strategy in a business ecosystem. Harvard Business School Working Paper, (03-061).

Englis et al. (2007), Knowledge and networks in the global startup process. Knowledge Management Studies, Vol 1, No 3/4, 2007.

MacCormack et al (2007), Innovation through Global Collaboration: A New Source of competitive advantage. Harvard Business School, Boston, Paper 07-079, 2007.

Kraut, R., \& Resnick, P. (2012), Introduction, Building Successful Online Communities, MIT Press

Romme, A. G. L., \& Endenburg, G. 2006. Construction Principles and Design Rules in the Case of Circular Design. Organization Science, 17(2): 287-297.

Adner, R. (2012), The Wide Lens, Harvard Business Press. 
Schilling, M., \& Hill, C. 1998. Managing the new product development process:

Strategic imperatives. Academy of Management Executive, 12(3): 67-81.

Den Ouden, Elke. 2012. Innovation Design - Creating Value For People, Organizations and Society. Springer

Snow, C. C., Fjeldstad, Ø. D., Lettl, C., \& Miles, R. E. 2011. Organizing continuous product development and commercialization: The collaborative community of firms model. Journal Of Product Innovation Management, 28(1): 3-16.

Kevin Boudreau. 2010. Open Platform Strategies and Innovation: Granting Access vs Devolving Control, Management Science, Vol 56, no 10, October 2010.

Snow et al. (2012). The Architecture Of Collaboration. Strat. Mgmt, 33: 734-750 (2012).

Casson \& Wadeson (2007), The Discovery of Opportunities: Extending the Economic Theory of the Entrepreneur. Small Business Economics, 28:285-300, 2007.

Iyer, B., Lee, C. H., \& Venkatraman, N. (2006). Managing in a small world ecosystem: Some lessons from the software sector. California Management Review, 48(3), 28-47.

Lee, C., Lee, K., \& Pennings, J. M. (2001). Internal capabilities, external networks, and performance: a study on technology-based ventures. Strategic Management Journal, 22(6-7), 615-640.

Witt, P. (2004). Entrepreneurs' networks and the success of start-ups. Entrepreneurship \& Regional Development, 16(5), 391-412. 
Sepulveda, F., \& Gabrielsson, M. (2013). Network development and firm growth: A resource-based study of B2B Born Globals. Industrial Marketing Management, 42(5), 792-804.

Aaboen et al.(2013), Strategizing as networking for new ventures. Industrial Marketing Management, Department of industrial Economics and Technology Management, NO-7491, 2013.

Elfring, T. \& Husink, W. (2003). Networks in entrepreneurship - the case of high technology firms. Small Business Economics, 21(4), 409-422.

Birley, S. (1986). The role of networks in the entrepreneurial process. Journal of Business Venturing, 1(1), 107-117.

Martinez, M., \& Aldrich, H. (2011). Networking strategies for entrepreneurs: balancing cohesion and diversity. International Journal of Entrepreneurial Behaviour \& Research. 17(1), 7-38.

Todeva, E. (2011), Entrepreneurial networks, in: Barnett, G. (ed.), Encyclopedia of Networks, SAGE, 261-264.

Phelps, R. Heidl, A. Wadhwa (2011). Knowledge, Networks, and Knowledge Networks: A Review and Research Agenda. 2012 Annual Review Issue of Journal of Management, Nov 1, 2011.

Nonaka,1994. A Dynamic Theory of Organizational Knowledge Creation. Organization Science, 5(1): 1994.

Nonaka, I., \& Takeushi, H. (1995). The knowledge-creating company. New York: Oxford University Press. 
Song et al. (2008). Success Factors in New Ventures: A Meta-Analysis*. Product Innovation Management 2008, 25:7-27.

Gartner, W. (1985). A Conceptual Framework for Describing the Phenomenon of New Venture Creation. Academy of Management Review, 1985 Vol.10, No. 4.

Yoffie, D., \& Kwak, M. (2006). With friends like these: The art of managing complementors, Harvard Business Review, Sep, 89-98.

Christensen et al. (2007), Finding the Right Job for Your Product. MIT Sloan Management Review, Spring 2007.

McPhee, Christopher Scott (2012). Using a Results-Based Organization Design Methodology to Construct the Technology Innovation Management Review. Carleton University, Dissertation. Engineering. Technology Innovation Management 2012.

Peffers et al. (2007). A Design Science Research Methodology for Information System Research. Journal of Management Information Systems, Volume 24 Issue 3, Winter 2007-8, pp.45-78.

Statistics Canada, 2000. Failure Rates for New Canadian Firms: New Perspectives on Entry and Exit. Ministry of Industry, February 2000, Catalogue no. 61-526-XIE 